\title{
Effects of soil moisture and dried raindroplet crust on saltation and dust emission
}

\author{
M. Ishizuka, ${ }^{1}$ M. Mikami, ${ }^{2}$ J. Leys ${ }^{3}$ Y. Yamada, ${ }^{4}$ S. Heidenreich, ${ }^{3}$ Y. Shao, ${ }^{5}$ \\ and G. H. McTainsh ${ }^{6}$ \\ Received 12 February 2008; revised 16 June 2008; accepted 17 September 2008; published 30 December 2008.
}

[1] Field experiments using a sand particle counter and an optical particle counter clarified the links between saltation and dust emission under wet and weakly crusted conditions in a fallow field previously cultivated with wheat in Australia. A crust was formed by the impact of raindroplets after small precipitation events. A little soil moisture enhanced the strengths of crust and aggregation even though the soil was dried. Dust concentration was proportional to friction wind velocity, but the proportionality was dependent on ground surface conditions, such as the minimally dispersed particle size distribution of parent soil and the presence or absence of crust.

Citation: Ishizuka, M., M. Mikami, J. Leys, Y. Yamada, S. Heidenreich, Y. Shao, and G. H. McTainsh (2008), Effects of soil moisture and dried raindroplet crust on saltation and dust emission, J. Geophys. Res., 113, D24212, doi:10.1029/2008JD009955.

\section{Introduction}

[2] The role of mineral dust in the atmosphere is becoming more important because of its impact on global climate change [Sokolik and Toon, 1996; Tegen et al., 1996]. To address this issue, international research projects have been carried out [e.g., Huebert et al., 2003; Mikami et al., 2006]. However, many uncertainties remains regarding (1) the direct effect of the scattering and absorbing of solar radiation and the indirect effect of modifications of cloud physical and radiative properties and precipitation processes [e.g., Kaufman et al., 2002], (2) the magnitude of nutrient and minerals losses from the land, (3) ocean ecosystem changes caused by changes in nutrient, iron and organic matter contents [e.g., Uematsu et al., 1983], and (4) the influence on society and people because of increased traffic and health hazards.

[3] Globally, dust is distributed by various physical processes, namely, saltation, dust emission, long-range transport, and wet and dry depositions. Of these processes, dust emission is the most effective for estimating precisely the amount of suspended dust. Since the 1970s, many dust emission models have been proposed, and it is convenient to categorize these for use. Shao and Dong [2006] classified

\footnotetext{
${ }^{1}$ Department of Safety Systems Construction Engineering, Faculty of Engineering, Kagawa University, Takamatsu, Kagawa, Japan.

${ }^{2}$ Meteorological Research Institute, Japan Meteorological Agency, Tsukuba, Japan.

${ }^{3}$ Department of Environment and Climate Change, New South Wales Government, Gunnedah, New South Wales, Australia.

${ }^{4}$ Rapid Engineering Team, Advanced Technology Support Division, RIKEN, Wako, Japan.

${ }^{5}$ Institute for Geophysics and Meteorology, University of Cologne, Cologne, Germany.

${ }^{6}$ Australian Rivers Institute, Griffith University, Nathan, Queensland, Australia.

Copyright 2008 by the American Geophysical Union. 0148-0227/08/2008JD009955\$09.00
}

them into three types, based on the model complexity [Zender et al., 2003]. (1) In $\alpha$-scheme models, the vertical dust flux $F$ (not necessarily the diffusive dust flux) is parameterized in terms of the power of the friction wind velocity $u *$ [e.g., Gillette, 1977; Gillette and Passi, 1988; Nickling and Gillies, 1989]. (2) In $\beta$-scheme models, $F$ is proportional to the streamwise saltation mass flux $Q$. This scheme comprises clay-content-dependent models [Marticorena and Bergametti, 1995], empirical models based on the observations [e.g., Nickling et al., 1999], energy-based models [Anderson, 1986; Shao et al., 1993; Alfaro and Gomes, 2001], and mass/volume-removal based models [Routbort et al., 1980; Rice et al., 1996a, 1996b; Lu and Shao, 1999]. (3) In $\gamma$-scheme models, three mechanisms are included: (1) aerodynamic entrainment, (2) saltation bombardment (sandblasting), and (3) aggregates disintegration [Shao, 2001, 2004]. While physically precise but complex dust emission models ( $\gamma$ scheme) have being developed, these simple models ( $\alpha$ and $\beta$ schemes) are still used in many general circulation models and regional dust simulations [Shao and Dong, 2006; Uno et al., 2006] because of the lack of precise parent soil particle size distribution (PSD) data in a global scale.

[4] Among three mechanisms for dust emission, aerodynamic entrainment does not effectively act on dust particles, because most of dust particles generally aggregate together and/or adhere to the surfaces of sand grains under natural field conditions. Interparticle cohesive and gravity forces bind particles together, in opposition to aerodynamic drag and lift forces [Iversen et al., 1976]. These interparticle cohesive forces become dominant in the case of dust particles because of the large decrease of gravity and aerodynamic forces associated with finer particle sizes [Shao, 2001]. Therefore, to release dust particles into the lower atmosphere additional force able to overcome the interparticle cohesive forces is required. Gillette [1977], Gomes et al. [1990], and Shao et al. [1993] have demonstrated from field 
measurements that sandblasting is the most efficient process providing this additional force. In this process, saltating sand particles strike the ground, breaking the interparticle cohesive forces, and releasing the dust particles [Rice et al., 1996b; Shao, 2001].

[5] Considering these processes dependent on the PSDs of parent soil, and saltating and suspended particles, Shao [2001] proposed the following dust emission model.

$$
\tilde{F}\left(D_{i}, D_{s}\right)=c_{Y}\left[(1-\gamma)+\gamma \frac{p_{m}\left(D_{i}\right)}{p_{f}\left(D_{i}\right)}\right] \frac{\hat{Q g}}{u_{*}^{2} m}\left(\rho_{b} \eta_{f i} \Omega+\eta_{c i} m\right),
$$

where $\tilde{F}$ is the dust emission rate for the $i$ th particle group of size $D_{i}$ generated by saltating particles of size $D_{s} ; c_{Y}$ is a dimensionless coefficient; $\gamma$ is a function of $u * ; p_{m}\left(D_{i}\right)$ is the minimally dispersed PSD of parent soil in bin number $i$; $p_{f}\left(D_{i}\right)$ is the fully dispersed PSD of parent soil in bin number $i$; $\hat{Q}$ is the vertical integrated streamwise saltation mass flux of $D_{s} ; g$ is acceleration due to gravity; $m$ is the mass of impacting saltation particle of size $D_{s} ; \rho_{b}$ is the bulk soil density; $\eta_{f i}$ is the fully dispersed fraction of dust which can be released from an unit soil for the $i$ th particle size group, which is the sum of the available (minimally dispersed) dust fraction $\eta_{m i}$ and aggregated dust fraction $\eta_{c i}$, namely

$$
\eta_{f i}=\eta_{m i}+\eta_{c i}
$$

and $\Omega$ is the volume removed by an impacting saltation particle of size $D_{s}$.

[6] The $\rho_{b} \eta_{f i} \Omega$ and $\eta_{c i} m$ in equation (1) are the dust emission components emitted by saltation bombardment and aggregates disintegration of particles of size $D_{s}$, respectively. Herein, $\rho_{b} \Omega / m$, which is the ratio of the mass ejected by bombardment $\rho_{b} \Omega$ to $m$, is equal to $\sigma_{m}$ in equation (6) of Shao [2004]; $\sigma_{m}$ is a function of the soil plastic pressure (hardness of ground surface) and was interpreted as a crust binding force; $(1-\gamma)+\gamma p_{m}\left(D_{i}\right) / p_{f}\left(D_{i}\right)$ is equal to the ratio of PSD of suspended particles $p_{s}\left(D_{i}\right)$ to $p_{f}\left(D_{i}\right)$ [Shao, 2001], where $p_{s}\left(D_{i}\right)$ is represented as

$$
p_{s}\left(D_{i}\right)=(1-\gamma) p_{f}\left(D_{i}\right)+\gamma p_{m}\left(D_{i}\right)
$$

It is assumed that $p_{m}\left(D_{i}\right)$ and $\eta_{c i}$ are related to the aggregation binding force.

[7] The crust and aggregation binding forces are the interparticle cohesive forces leading to suppression of dust emission. It is essential to overcome these forces for dust emission to take place, but there is still uncertainty regarding these two forces owing to difficulties of measurement and complexities of the microphysical mechanisms. With respect to saltation, a number of studies have been clarified the effects of ground surface conditions on saltation [e.g., Chepil, 1956]. As for dust emission, however, until now, the effects of soil moisture or the presence of a physical crust have not been characterized in detail. There is a particular need for more observation data of both saltating and suspended particles of different sizes under different ground surface conditions to update the present dust emission model.
[8] The purpose of this study was to clarify the effects of soil moisture and the presence of a weak physical crust on saltation and dust emission. This study investigated the particle size characteristics of suspended dust and parent soil under uncrusted or weakly crusted dry conditions, in a field, previously cultivated with wheat, that was showing signs of erosion before crust development.

\section{Interparticle Cohesion}

\subsection{Classification}

[9] Interparticle cohesion contributes to the suppression of saltation and dust emission. We drew a schematic diagram of interparticle cohesion (Figure 1) based on information available in the literatures [e.g., Iversen and White, 1982; Shao, 2000]. In brief, interparticle cohesion results from the combined effects of van der Waals, electrostatic, chemical, biological, and liquid (physical) forces. All of these forces are related to soil properties, such as particle size, particle shape, particle surface texture, soil mineralogy, packing arrangement, and the presence or absence of binding agents such as soil moisture, soluble salts, and cryptogams.

[10] We divided the soil properties relevant to wind erosion into three categories: internal, intermediate, and external factors. Internal factors are related to the soil particles themselves, whereas soil moisture, which is input from outside systems (e.g., rain, snow, and irrigation), is an external factor. Soil moisture is easy to measure, and studies of soil moisture have been conducted since the work of Chepil [1956]. Soluble salts are an example of an intermediate factor, one which is only a weak binding force by itself. However, once salts are dissolved, mobilized, and dried, their binding force strength becomes large and can cause the formation of hard crusts. Cryptogams, such as moss, fungi, and algae, are also categorized as intermediate factor, because they take a long time to grow. The total cohesive force strength depends on the combination of the particle properties, the quantity and state of binding agents such as salts and cryptogams, and the wetness of the ground surface.

\subsection{Threshold Friction Wind Velocity}

[11] The mobilization of soil particles is initiated when $u_{*}$ exceeds threshold friction wind velocity $u_{*} . Q$ is strongly controlled by $u_{*}$ and $u_{*}$, and $\tilde{F}$ is controlled by $Q$, PSD of parent soil, and ground surface conditions (equation (1)). The determination of $u_{*}$ is critical for saltation. Bagnold [1941] derived a simple relationship between $u_{*}$ and the sand particles, based on gravity force and aerodynamic drag. Iversen et al. [1976] studied interparticle cohesive forces acting on spherical particles in addition to the simple relationship described by Bagnold [1941], and proposed a $u *_{t}$ for the entire particle size range by considering interparticle cohesive forces and aerodynamic lift. They showed that $u_{*}$ increased with decrease of particle sizes, those less than around $80 \mu \mathrm{m}$. Their equation was later simplified for loose, dry, bare surfaces by Shao and Lu [2000].

[12] The parameter $u_{*}$ is very dynamic in response to changes in surface parameters such as soil moisture, salt content, surface crust, and vegetation. Pragmatically, these 


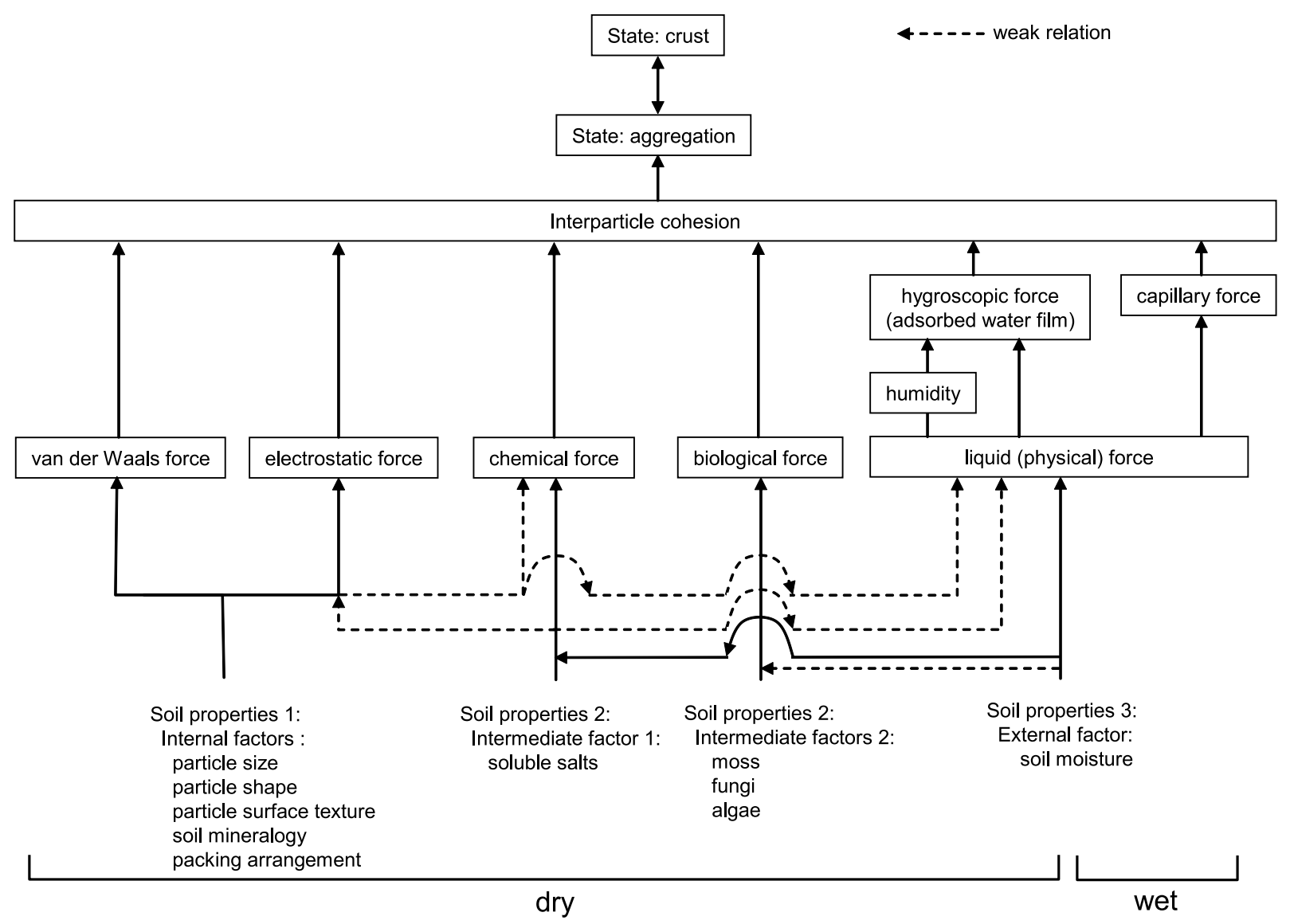

Figure 1. Schematic diagram of interparticle cohesions.

effects of these parameters on $u_{*_{t}}$ are individually and explicitly considered in the following relation [Shao, 2000].

$$
\begin{gathered}
u_{* t}\left(D_{s} ; \lambda, \theta, s c, c r, \cdots\right)=u_{* t}\left(D_{s}\right) f_{\lambda}(\lambda) f_{w}(\theta) f_{s c}(s c) \\
f_{c r}(c r) \cdots
\end{gathered}
$$

where $u_{*_{t}}\left(D_{s}\right)$ is $u_{*_{t}}$ for sand particles of size $D_{s}$ in the idealized situation when the soil is dry, bare, and free of crust or salt; and $f_{\lambda}(\lambda), f_{w}(\theta), f_{s c}(s c)$, and $f_{c r}(c r)$ are the weight functions of surface roughness elements $\lambda$, soil moisture $\theta$ (volumetric water content), salt content $s c$, and surface crustiness $c r$, respectively. As related to interparticle cohesion, soil moisture, salt content, and surface crustiness are generally measurable parameters. Soil moisture and soluble salts can lead to the formation of a crust when the soil dries [Nickling and Ecclestone, 1981; Rice et al., 1997]. In this study we define "crust," from a macroscopic point of view, as the aggregated state of a dry ground surface.

\subsection{Soil Moisture}

[13] Many studies have reported that as soil moisture increases, $Q$ decreases [e.g., Chepil 1956], because $u_{*_{t}}$ increases [e.g., McKenna-Neuman and Nickling, 1989; Fécan et al., 1999]. A recent study in the Taklimakan Desert [Ishizuka et al., 2005a] used a sand particle counter (SPC) to show that the saltation mass flux $q(z)$ at the reference height $z$ is particle size and soil moisture dependent, and, moreover, that a simple relationship exists between $q(z)$ and wind speed $u$, and between $q(z)$ and threshold wind speed $u_{t}(\theta)$. However, many uncertainties still remain regarding soil moisture, relating, for example, to the roles of hygroscopic, low-capillary, crust binding, and aggregation binding forces.

\subsection{Crusts}

[14] Various types of soil crust occur in arid and semiarid regions. We classified soil crusts into physical, chemical, and biological crusts (Figure 1). The cement-like or platelike crust, often with cracks, on the clay surface of a dried lake bed is a typical example of a strong physical crust that reduces the wind erosion rate [Gillette et al., 1980]. Rice et al. [1996b] reported that dislodgment of surface particles decreased with increasing crust strength in a laboratory experiment using artificially produced crusts.

[15] In arid environments, soluble salts can form crystallized or cemented chemical crusts. Nickling and Ecclestone [1981] and Nickling [1984] showed that $u_{*_{t}}$ was exponentially related to salt concentration on the basis of wind tunnel experiments. Biological (cryptogamic) crusts are also important. McKenna-Neuman et al. [1996] and McKennaNeuman and Maxwell [1999] tested the surface protection provided by crusts formed by fungi and photoautotrophic microorganisms in a wind tunnel. Leys and Eldridge [1998] demonstrated that cryptogamic crusts effectively controlled wind erosion of both loamy and sandy rangeland soils in their study area. 


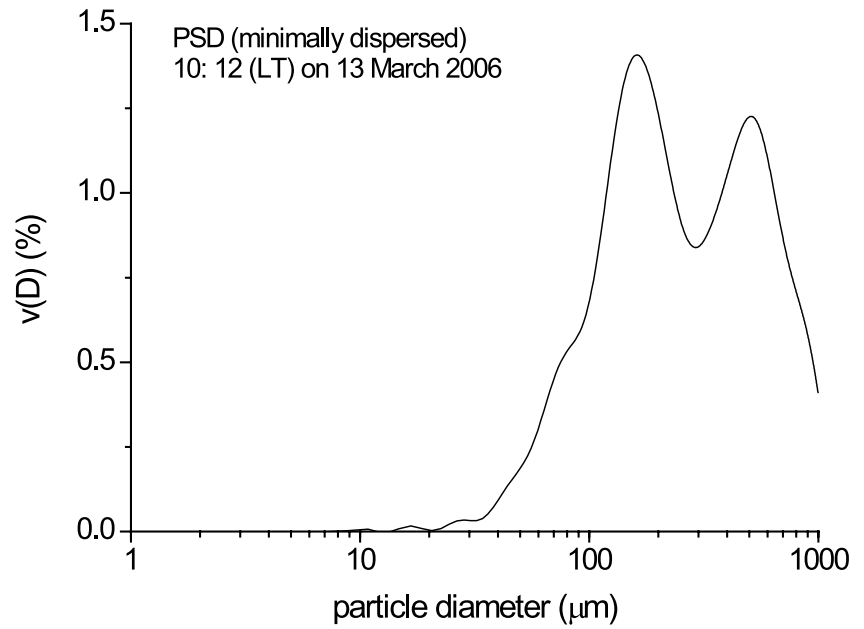

Figure 2. Particle size distribution under minimally dispersed conditions of a sample collected at 1012 LT on 13 March 2006. The curve was drawn by the MIX curve-fitting method, with B-spline interpolation of the smoothed data.

[16] In this study, we examined the weak physical crust that forms as a result of the impact and subsequent drying of raindroplets striking a dry soil surface. These crusts are very weak and can be easily destroyed by touching them.

\section{Methods}

\subsection{Intensive Observation Period}

[17] The Japanese Australian Dust Experiment (JADE) is a project launched in April 2005. The project aimed to clarify the link between saltation and dust emission by intensive observation, theory, and modeling. Intensive observation (JADE-Intensive Observation Period (IOP)) was carried out during autumn 2006 (23 February to 13 March) in a fallow field previously cultivated with wheat in Australia.

\subsection{Site}

[18] Our observation site was located at Petro Station $\left(33^{\circ} 50^{\prime} 39.3^{\prime \prime} \mathrm{S}, 142^{\circ} 43^{\prime} 52.3^{\prime \prime} \mathrm{E}\right), 80 \mathrm{~km}$ northeast of Mildura, Victoria, in the Murray-Darling River Basin in Australia. This area is known as a "hot spot" for dust events in Australia [McTainsh et al., 1990]. The field, which extended about $1 \mathrm{~km}$ in the $\mathrm{E}-\mathrm{W}$ direction and about $4 \mathrm{~km}$ in the $\mathrm{N}-\mathrm{S}$ direction, had been last cultivated in spring 2005 and, at the time of the study in autumn 2006, was already showing signs of major erosion.

[19] The prevailing wind blows from the south, but strong winds sometimes blow from the northwest. To secure a long fetch, the instruments were located $800 \mathrm{~m}$ from the western edge and $200 \mathrm{~m}$ from the eastern edge of the field. The parent soil was a loamy sand with clay content of close to $13 \%$, silt content of $11.5 \%$, and sand content of $75.5 \%$. There was little vegetation (13\% plant litter and stone) in the field, and the surface roughness was small because of the recent erosion. The soil salt content was negligible. No physical, chemical, or biological crusts had formed in this cultivated paddock (or field) before JADE-IOP.

\subsection{Particle Size Distribution of the Parent Soil}

[20] Figure 2 shows the parent soil PSD $p_{m}(D)$ measured under minimally dispersed conditions, sampled at a $0-0.5 \mathrm{~cm}$ depth on 13 March 2006. Minimally dispersed measurement is an excellent technique to measure the undisturbed, in situ PSD formed aggregates or coat the sand particles and to identify changes in the finer particle range. This was measured with a Coulter Multisizer particle counter, which analyze the PSD with high resolution and classifies the sample according to 256 particle size classes from $1 \mu \mathrm{m}$ to the size range of the top class $(500-1200 \mu \mathrm{m})$ depending on the experimental setting [McTainsh et al., 1997]. The PSD of the parent soil at the size was bimodal with population peaks at 173 and $570 \mu \mathrm{m}$ as determined by the MIX curve fitting method [Leys et al., 2005]. The coarse 570- $\mu$ m mode occupied $27 \%$ of the distribution.

[21] In contrast, in the more usual method for measuring PSD, the particles are fully dispersed, that is, completely separated by chemically. In relation to dust emission, $p_{m}(D)$ would show the in situ size distribution of particle, which is important to understand the actual dust emission flux, changing by the ground surface conditions. Whereas $p_{f}(D)$ would show PSD fundamentally existed in the parent soil, which might be important to estimate the upper limit of dust emission flux.

\subsection{Wind Erosion Measurements}

[22] To measure saltation, we used an SPC, manufactured by Niigata Electric Co., Ltd. in Niigata, Japan, able to measure the number of saltating sand particles from $38 \mu \mathrm{m}$ to $654 \mu \mathrm{m}$ in diameter every second with 32 channels [Yamada et al., 2002]. This instrument has been used previously in the Taklimakan Desert [Ishizuka et al., 2005a; Mikami et al., 2005b; Shao and Mikami, 2005]. In addition, dust emission was measured with a newly developed optical particle counter (OPC), manufactured by YGK Corporation in Yamanashi, Japan [Mikami et al., 2005a]. This OPC counts the number of suspended dust particles with 8 channels, $0.3-$ $0.5,0.5-0.7,0.7-1,1-2,2-3,3-5,5-7$, and $>7 \mu \mathrm{m}$ in diameter, every second. SPCs and OPCs were installed at the same site at different heights: SPCs were placed at $0.05,0.1$, $(0.2)$, and $0.3 \mathrm{~m}$ from the ground surface, and OPCs were placed at heights of 1.0, 2.0, and $3.5 \mathrm{~m}$ (Table 1).

\subsection{Hydrometeorological Measurements}

[23] Automatic weather stations (AWS) were installed to measure hydrometeorological data: wind speed, wind direction, air temperature, relative humidity of air, four solar radiation components, soil moisture, soil temperature, raindrop signal and precipitation. The instrument specifications and placement are listed in Table 1. All instruments were powered by solar panels and a petrol generator. All meteorological and hydrological data were recorded at 1-min intervals.

[24] Time domain reflectometry (TDR)-type soil moisture sensors (CS616, Campbell Scientific Inc.) were set in the soil surface layer at three depths $(0.2-2,2.5-3.3$, and $4.6 \mathrm{~cm})$. Both the CS616 sensor and the earlier model CS615 have been successfully tested in laboratory experiments for use in hyperarid environments [Ishizuka and Mikami, 2005], and CS615 has also been used in field studies in the Taklimakan Desert [Ishizuka et al., 2005b]. For the sensor calibration, which was done on site, the soil was sampled at four depths $(0-0.5,1.5-2.5,2.8-3.8$, and $4.1-5.1 \mathrm{~cm})$. The gravimetric soil water content $\omega_{\text {oven }}$ of these samples was measured on an 
Table 1. Instrumental Settings at the Site During JADE-IOP

\begin{tabular}{|c|c|c|c|}
\hline Measurement Item & Height or Depth & Type & Manufacturer \\
\hline Saltating particle number & $0.05,0.1,(0.2)$, and $0.3 \mathrm{~m}$ & $\mathrm{SPC}$ & Niigata Electric Co., Ltd. \\
\hline Suspended particle number & $1.0,2.0$, and $3.5 \mathrm{~m}$ & $\mathrm{OPC}$ & YGK Corp. \\
\hline Wind speed & $0.50^{\mathrm{a}}$ and $2.16 \mathrm{~m}$ & 014A & Met One Instruments, Inc. \\
\hline Wind direction & $2.16 \mathrm{~m}$ & 024A & Met One Instruments, Inc. \\
\hline Air temperature & $1.015^{\mathrm{b}}$ and $2.813 \mathrm{~m}^{\mathrm{b}}$ & HMP45D & Visala Corp. \\
\hline Relative humidity & $1.015^{\mathrm{b}}$ and $2.813 \mathrm{~m}^{\mathrm{b}}$ & HMP45D & Visala Corp. \\
\hline Radiation $(\mathrm{SR} \downarrow, \mathrm{SR} \uparrow, \mathrm{LR} \downarrow, \mathrm{LR} \uparrow)^{\mathrm{c}}$ & $1.56 \mathrm{~m}$ & CNR1 & Kipp \& Zonen B.V. \\
\hline Rain droplet signal & $1.3 \mathrm{~m}$ & PPS-01 (C-PD1) & PREDE Co., Ltd. \\
\hline Precipitation & $0.3 \mathrm{~m}$ & rain gauge & \\
\hline Soil temperature & $2,3.3$, and $4.6 \mathrm{~cm}$ & C-PT & Climatec Inc. \\
\hline Soil water & $0.2-2,2.5-3.3$, and $4.6 \mathrm{~cm}$ & CS616 & Campbell Scientific Inc. \\
\hline
\end{tabular}

oven-dry basis every day during the IOP. A total of 79 samples were tested.

[25] Precipitation was measured by a rain gauge with a resolution of $0.2 \mathrm{~mm}$. In addition, a rain sensor (PPS-01(C-PD1), PREDE Co., Ltd.) was used. Although this instrument cannot measure the amount of precipitation, it can accurately measure the starting time of rainfall. Therefore, the rain sensor is suitable for detecting very small rain events.

\subsection{Calculation of the Friction Wind Velocity}

[26] Wind speed and air temperature profiles were used to calculate the $u_{*}$. Generally, in arid regions, the surface boundary layer is strongly unstable in daytime and stable at night. When the wind speed is low, the accuracy of the $u$ * calculation is decreased by instability of the boundary layer.

[27] In this study, before we calculated $u_{*}$, we determined the roughness height $z_{0 \mathrm{~m}}$ at the zero-plane and the zeroplane displacement $d_{0}$ using the 10-min averaged wind speed and air temperature profiles, based on the data originally measured at 1-min intervals. Among the collected data, we selected the 10-min averaged wind directions between $200^{\circ}$ and $340^{\circ}$ to avoid distortion caused by the disturbance of other instruments on the SPC. In addition, data collected during strong winds, defined as 10-min averaged wind speeds larger than $8 \mathrm{~m} / \mathrm{s}$ at $2.16 \mathrm{~m}$ height, were used to ensure stable boundary layer conditions. The calculations of $z_{0 \mathrm{~m}}$ and $d_{0}$ were iteratively performed using the selected wind and air temperature profiles. We obtained $z_{0 \mathrm{~m}}$ equal to $0.48 \mathrm{~mm}$. This value is reasonable for a bare, unvegetated field [Oke, 1978].

[28] In our observation, the anemometer at lower height was set at $0.5 \mathrm{~m}$. Theoretically, $q(z)$ is quite low when $z$ is higher than $0.1 \mathrm{~m}$ height from the ground surface [Shao, 2005]. Influence of saltation layer on wind profile is less effective to calculate $u *$. Finally, we estimated $u *$, the friction temperature $T_{*}$, and the Monin-Obukhov length $L$ for every minute, setting $z_{0 \mathrm{~m}}=0.48 \mathrm{~mm}$ and $d_{0 \mathrm{~m}}=0 \mathrm{~mm}$, using the maximum correlation method, which iteratively minimize the correlation coefficient between observed profiles and $\log$ profiles of wind speed and air temperature [Mikami et al., 1996].

\subsection{Calculation of the Saltation Mass Flux}

[29] The $q(z)\left(\mathrm{M} \mathrm{L}^{-2} \mathrm{~T}^{-1}\right)$ is a integration of $\hat{q}\left(z, D_{s i}\right)$, that is, the saltation mass flux of saltation particles of volume-averaged diameter $D_{s i}$ in bin number $i$ at the reference height $z$, as in the following equation:

$$
q(z)=\sum_{i=1}^{N_{\max }} \hat{q}\left(z, D_{s i}\right),
$$

where $\hat{q}\left(z, D_{s i}\right)$ is calculated by using SPC data with equation (6), below; and $N_{\max }$ is the maximum number of bins $(=28$, the number of SPC channels available for the analysis after temperature correction [Mikami et al., $2005 \mathrm{~b}])$. The $q(z)$ was calculated for particles ranging from $84\left(=D_{s 1}\right)$ to $629 \mu \mathrm{m}\left(=D_{s N \max }\right)$ in diameter.

[30] Assuming a spherical particle shape, $\hat{q}\left(z, D_{s i}\right)$ is given by

$$
\hat{q}\left(z, D_{s i}\right)=\frac{\pi D_{s i}^{3} \rho_{s}}{6 A T} N_{s}\left(z, D_{s i}\right)
$$

where $\rho_{s}$ is the density of the particles, set at $2645 \mathrm{~kg} / \mathrm{m}^{3} ; A$ $(=2 \mathrm{~mm} \times 25 \mathrm{~mm})$ is the measurement area of the SPC slit between the transmitter and the semiconductor laser detector, through which the particles pass; and $N_{s}\left(z, D_{s i}\right)$ is the integrated number of particles of size $D_{s i}$ during integration time $T$ (=60 s) measured by the SPC mounted at height $z$.

\subsection{Calculation of the Dust Concentration}

[31] The dust concentration $c(z)$ at a reference height $z$ was calculated by using the following equation:

$$
c(z)=\sum_{i=1}^{I_{\max }} \hat{c}\left(z, D_{d i}\right),
$$

where $\hat{c}\left(z, D_{d i}\right)$ is the $c(z)$ for dust particles of diameter $D_{d i}$ in bin number $i$. This is calculated from OPC data by using equation (8), below. $D_{d i}$ is $\sqrt{D_{d i} D_{d(i+1)}}$ in bin number $i ; D_{d i}$ and $D_{d(i+1)}$ are the minimum and maximum particle diameters in bin $i$; and $I_{\max }$ is the maximum number of bins available for the analysis $(=6) . D_{d 1}$ was $0.5 \mu \mathrm{m}$, and $D_{d\left(I_{\max }+1\right)}$ was $7.0 \mu \mathrm{m}$.

[32] Assuming spherical particles, $\hat{c}\left(z, D_{d i}\right)$ is given by the following equation:

$$
\hat{c}\left(z, D_{d i}\right)=\frac{\pi D_{d i}^{3} \rho_{s}}{6 P} N_{d}\left(z, D_{d i}\right)
$$


Table 2. Dust Events During JADE-IOP

\begin{tabular}{cccc}
\hline Dust Event & $\begin{array}{c}\text { Date On (LT) } \\
(\mathrm{yy} / \mathrm{mm} / \mathrm{dd} \text { hmm })\end{array}$ & $\begin{array}{c}\text { Date Off (LT) } \\
(\mathrm{yy} / \mathrm{mm} / \mathrm{dd} \text { hhmm) }\end{array}$ & $\begin{array}{c}\text { Duration } \\
(\mathrm{hhmm})\end{array}$ \\
\hline Event 10 & $2006 / 03 / 120955$ & $2006 / 03 / 121913$ & 0918 \\
Event 11 & $2006 / 03 / 122112$ & $2006 / 03 / 130208$ & 0456 \\
Event 12 & $2006 / 03 / 130954$ & $2006 / 03 / 131858$ & 0904 \\
\hline
\end{tabular}

${ }^{\mathrm{a}} \mathrm{LT}$ denotes local time. UTC is LT $-11 \mathrm{~h}$.

where $N_{d}\left(z, D_{d i}\right)$ is the OPC-measured number of particles of size $D_{d i}$ at the reference height $z$ integrated over one minute of airflow at the air pump flow rate $P(=100 \mathrm{ml} / \mathrm{min})$. Herein, the units of $\hat{c}\left(z, D_{d i}\right)$ are $\mu \mathrm{g} / \mathrm{m}^{3}$. Strictly speaking, dust particles are not spherical, and the aspect ratio should be considered. However, we have no data from our site on the aspect ratio, which is difficult to measure for every particle every second by present instrumental techniques. Our result could be validated with knowing some probability density function for the aspect ratio.

\section{Wind Erosion Events}

\subsection{Meteorological Conditions}

[33] It was hot and dry during JADE-IOP. According to the monthly climate summary provided by the Austrian Government Bureau of Meteorology (http://www.bom.gov. au/announcements/media_releases/vic/20060403.shtml), March 2006 was marked by prolonged periods of high pressure centered in the Tasman Sea. These high-pressure systems directed warm northerly winds over Victoria and kept conditions sunny for most of the month. On 12 and 13 March, the dry conditions were interrupted by a cold front and an accompanying rainband.

[34] During the IOP, the mean air temperature at the site was $26.0^{\circ} \mathrm{C}$ and the relative humidity was $31.6 \%$. The maximum recorded air temperature was $42.1^{\circ} \mathrm{C}$. The mean soil temperature at $2 \mathrm{~cm}$ depth was $31.3^{\circ} \mathrm{C}$, and the maximum and minimum soil temperatures were 53.3 and $9.3^{\circ} \mathrm{C}$, respectively.

\subsection{Dust Events}

[35] The soil moisture was very low and did not constrain dust emission during JADE-IOP except on the last two days (12 and 13 March). There were 12 dust events in all, as indicated by the SPC data. Four very small $(<0.2 \mathrm{~mm})$ rainfall events were observed on 12 and 13 March. Despite these lowprecipitation events, strong dust events were still observed. Of the 12 dust events, we concentrate here on the last three events: events 10,11 and 12 (Table 2 and Figure 3), when the ground surface conditions were changed by precipitation and crust formation, providing a good opportunity to evaluate the effects of soil moisture and crust formation on wind erosion processes. Figures 3 and 4 show the temporal variations in the wind direction and $u_{*}$, and $q(z)$, respectively. We divided events 10 and 11 into subevents, labeled with numbers and letters, on the basis of SPC and $u *$ data.

[36] Event 10 began on 9:55 local time (LT) on 12 March and continued for $9 \mathrm{~h} 18 \mathrm{~min}$. This event can be broken into two parts. Subevent 10-A began at 0955 LT and ended at 1746 LT. The wind was predominately from the NW, with a decreasing wind speed, during this event. The maximum SPC reading during 10-A was at 1022 LT (Figure 4). The second highest peak of $q(z)$ during the IOP occurred later in the day during 10-B and was associated with a short burst of a maximum wind speed of $11.3 \mathrm{~m} / \mathrm{s}$ at $2.16 \mathrm{~m}$ height $\left(u_{*}=\right.$ $0.53 \mathrm{~m} / \mathrm{s}$ ), as well as with a change in wind direction from the NW to the SW for about $11 \mathrm{~min}$ and a small amount of precipitation (event $r_{1}$ ) (Figures 5 and 6). We validate rain sensor signal $r$ in section 4.3.

[37] Event 11 was characterized by a wind direction change (from $\mathrm{N}$ to SE). The highest peak of $q(z)$ during the IOP was recorded at 21:13 LT on 12 March (11-D; Figure 4$)$ with wind speed of $12.6 \mathrm{~m} / \mathrm{s}$ at a $2.16 \mathrm{~m}$ height $\left(u_{*}=\right.$

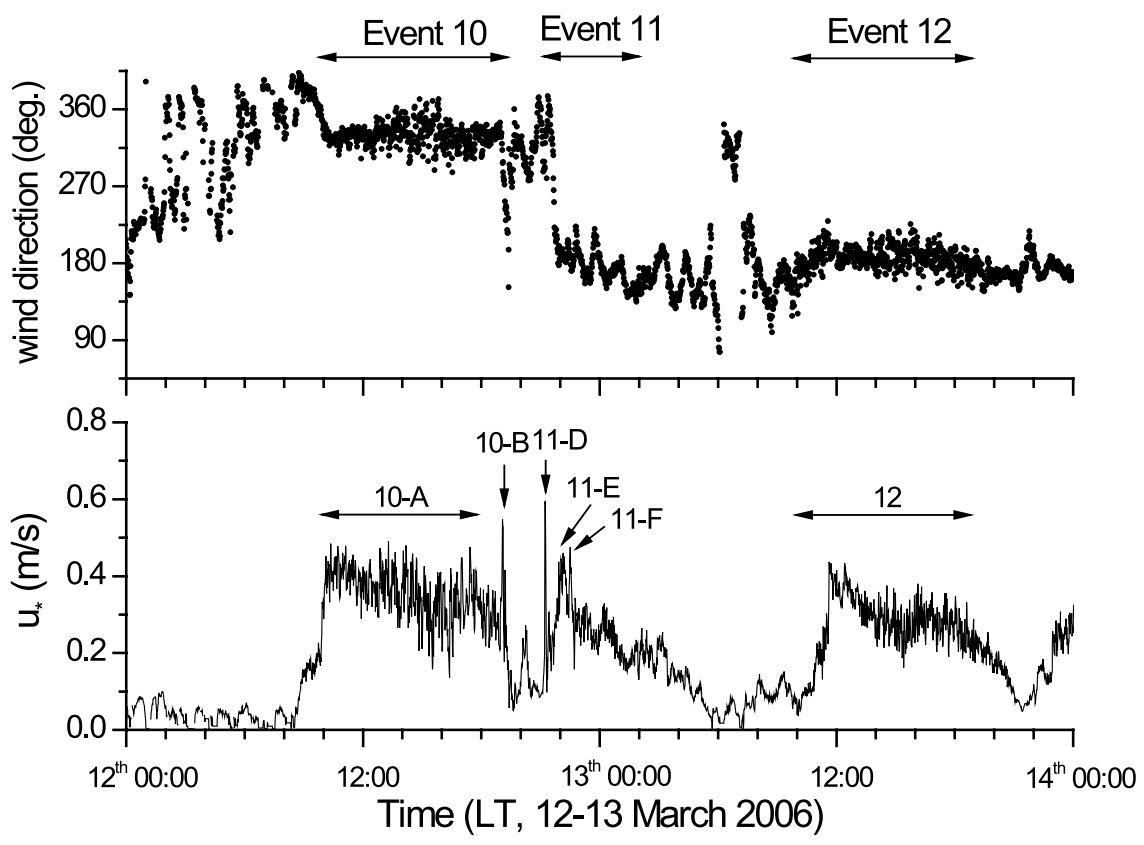

Figure 3. Temporal variations in friction wind velocity $u_{*}$ and wind direction. $u_{*}$ and wind direction were averaged over 1-min intervals. 


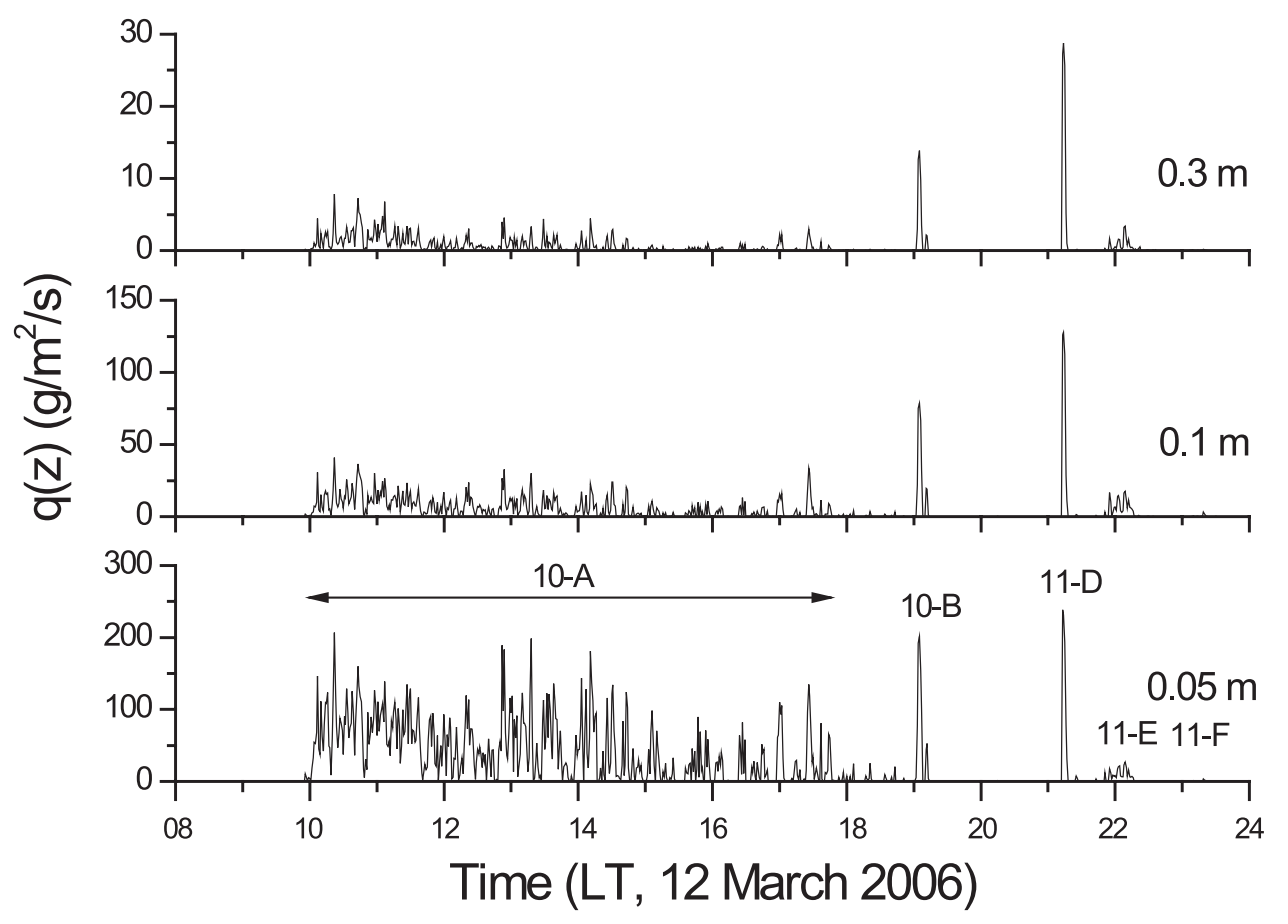

Figure 4. Temporal variations in the total saltation mass fluxes $q(z)$ at heights of $0.05,0.1$, and $0.3 \mathrm{~m}$ on 12 March 2006.

$0.59 \mathrm{~m} / \mathrm{s}$ ) accompanied by a small amount of precipitation $\left(r_{2}\right)$ (Figure 6). Two other subevents (11-E and 11-F) were also recorded at 2150-2216 LT and 2226-2234 LT on the same day, when southerly winds were prevalent.

[38] Event 12 started at 0954 LT on 13 March after precipitation event $r_{4}$ and crust formation. Winds blew from the south, $u *$ ranged from 0.2 to $0.43 \mathrm{~m} / \mathrm{s}$, and the maximum of $u *$ was a little lower than that during events 10 and 11 .

[39] The $q(z)$ showed a clear height dependence (Figure 4): $q(z)$ recorded at a $0.05 \mathrm{~m}$ height was greater than that recorded at 0.1 and $0.3 \mathrm{~m}$ heights, as reported by previous studies
[Zobeck and Fryrear, 1986, Mikami et al., 2005b; Shao, 2005].

[40] Owing to the instrumental setup of the SPCs (see the photograph provided by Mikami et al. [2005b]), the data are compromised for some wind directions. In this experiment, the horizontal crossbar supporting the SPCs was orientated $\mathrm{N}-\mathrm{S}$. The SPC at $0.05 \mathrm{~m}$ height was the closest to the southern support pole. Thus, when the wind blew from the south, the 0.05-m SPC was in the shadow of the pole, resulting in underestimation of the particle count. This interpretation is supported by data that indicate that $q(0.05 \mathrm{~m})$ was less than

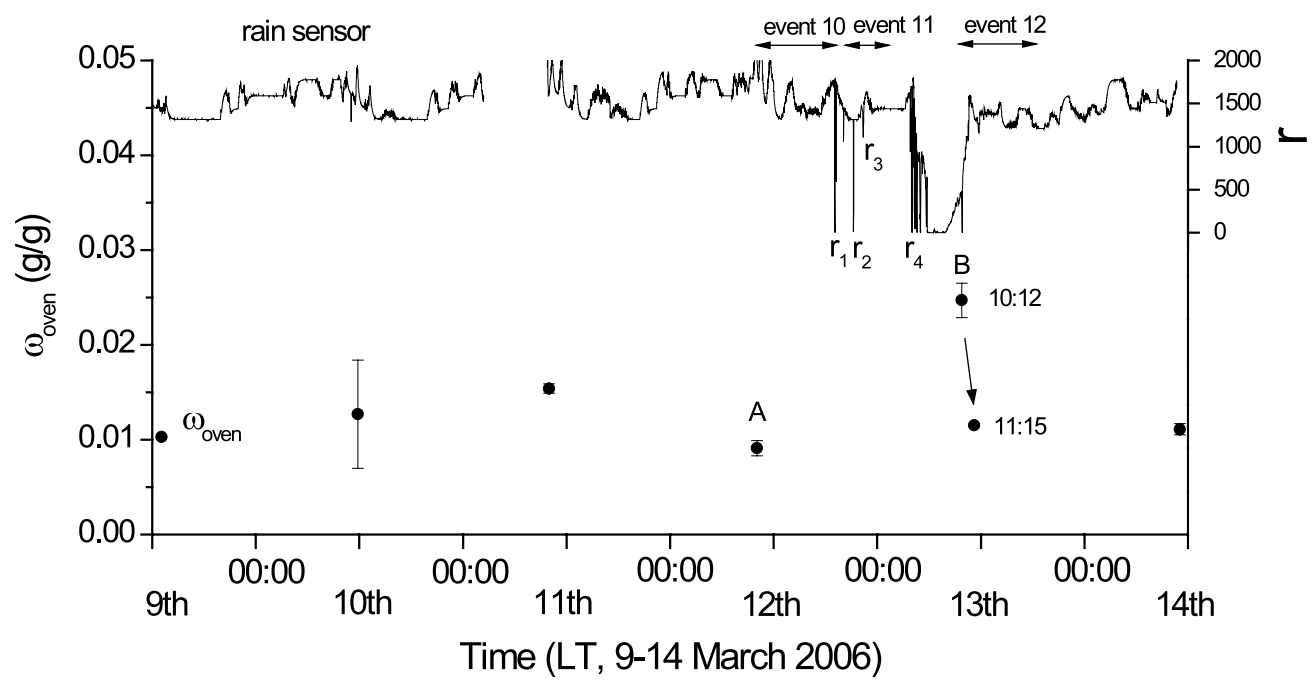

Figure 5. Gravimetric soil water content $\omega_{\text {oven }}$ at $0-0.5 \mathrm{~cm}$ depth measured on an oven dry basis (dot). Error bars show the standard deviation. Temporal variations in the rain sensor signal $r$ (line). No data were recorded during 0224-0946 LT on 11 March 2006. 

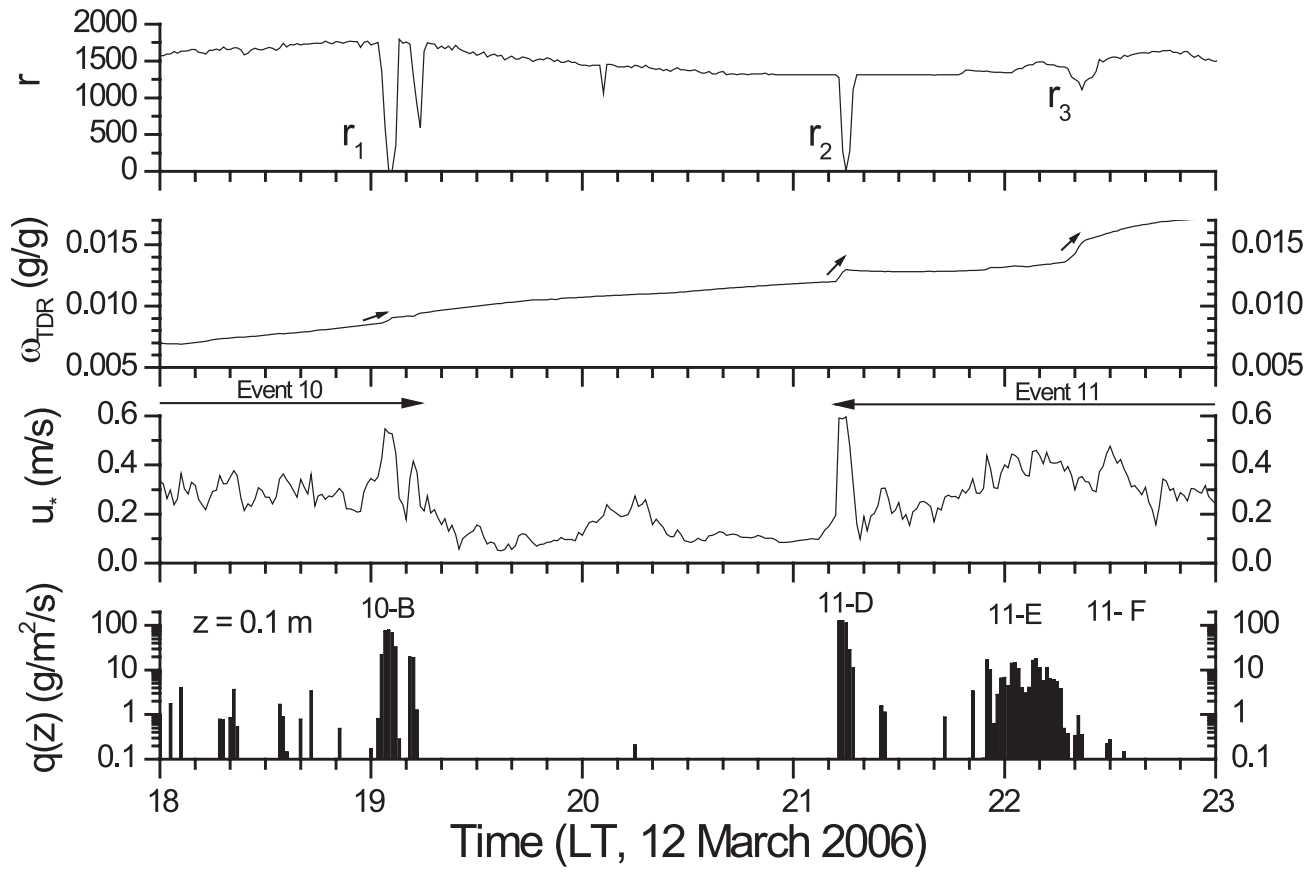

Figure 6. Temporal variations in the rain sensor signal $r$, the TDR-measured soil water content $\omega_{T D R}$ at $0.2-2 \mathrm{~cm}$ depth, $u_{*}$, and $q(z)$ at $0.1 \mathrm{~m}$ height during subevent $10-\mathrm{B}$, and subevents $11-\mathrm{D}, 11-\mathrm{E}$, and 11-F. Subevent 11-E was from 2150 to 2216 LT, and subevent 11-F was from 2226 to 2234 LT.

$q(0.1 \mathrm{~m})$ when the wind direction was $180 \pm 10^{\circ}$. Therefore, the $q(0.05 \mathrm{~m})$ data for this wind direction range (event 12 data) were excluded from our analysis. $q(0.1 \mathrm{~m})$ and $q(0.3 \mathrm{~m})$ did not show any sign of such a flux inversion, so these data were included in the analysis. Events 10 and 11 showed no signs of interference from the support poles.

\subsection{Precipitation Events}

[41] Before 12 March, no precipitation was observed during the IOP and the surface soil was very dry; the gravimetric water content $\omega_{\text {oven }}$ at $0-0.5 \mathrm{~cm}$ depth was about $0.01 \mathrm{~g} / \mathrm{g}$ (Figure 5). However, from the evening of $12 \mathrm{March}$ to the morning of $13 \mathrm{March}$, the rain sensor detected several very small precipitation events (Figures 5 and 6), indicated by falls in the signal $r$ of the rain sensor. These events, designated $r_{1}, r_{2}, r_{3}$, and $r_{4}$, were not detected by the tippingbucket rain gauge, indicating that the total precipitation associated with each event was less than $0.2 \mathrm{~mm}$. We actually observed these rain events while we were on the site or at the base camp, some $10 \mathrm{~km}$ from the site.

[42] For $r_{1}, r_{2}$, and $r_{3}$, no soil sampling data were collected because they occurred in the evening, but the surface soil at $0-0.5 \mathrm{~cm}$ depth was sampled in the morning after event $r_{4}$, at 1012 LT on 13 March and then again at 1115 LT (Figure 5). $\omega_{\text {oven }}$ at 1012 LT had increased to $0.025 \mathrm{~g} / \mathrm{g}$ compared with the values before the precipitation events, and the ground surface was visibly wet, but by 1115 LT $\omega_{\text {oven }}$ had decreased to $0.012 \mathrm{~g} / \mathrm{g}$, and the ground surface was already dry because of rapid evaporation.

[43] The temporal variation of gravimetric soil water content $\omega_{T D R}$, measured by TDR sensor is also shown in Figure 6 . The $\omega_{T D R}$ was calculated from the TDR-measured volumetric soil water content $\theta_{T D R}$ using the relation $\omega_{T D R}=\theta_{T D R} /(1-n) \rho_{S}$, assuming a uniform $\rho_{s}$ and porosity $n(=0.47)$, and calibrated by using $\omega_{\text {oven }}$ determined on samples from the site. Before this calculation, the temperature dependence of $\theta_{T D R}$ was calibrated using calibration equations provided from the manufacturer [Campbell Scientific, Inc., 2002]. The quick responses of $\omega_{T D R}$ at $0.2-2 \mathrm{~cm}$ depth corresponded to the precipitation events shown by the decrease in $r$ in Figure 6. A fact of small amount of precipitation was clearly measured by the TDR sensor.

\section{Results}

\subsection{Effect of Soil Moisture on $q(z)$}

[44] Three rainfall events $\left(r_{1}, r_{2}\right.$, and $\left.r_{3}\right)$ resulted in quick increases in surface soil moisture $\omega_{T D R}$ (Figure 6). The first two rain events $\left(r_{1}\right.$ and $\left.r_{2}\right)$ had little impact on $q(0.1 \mathrm{~m})$

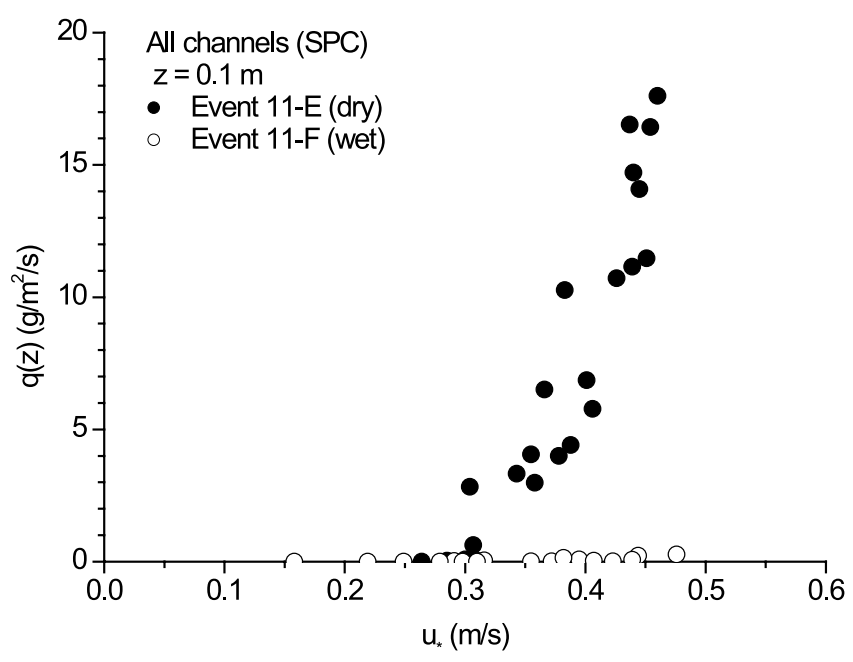

Figure 7. Relationship between $u_{*}$ and saltation flux $q(z)$ at $0.1 \mathrm{~m}$ height under wet and dry conditions, during subevents 11-E and 11-F. 


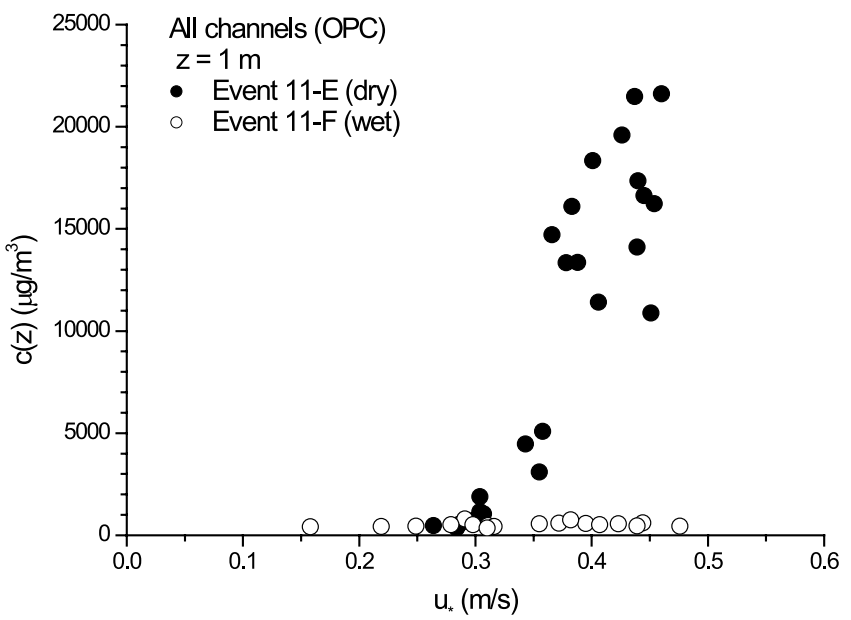

Figure 8. Relationship between $u_{*}$ and the dust concentration $c(z)$ at $1 \mathrm{~m}$ height during subevents $11-\mathrm{E}$ and 11-F.

during dust subevents 10-B, 11-D, and 11-E. However, once $\omega_{T D R}$ exceeded about $0.013 \mathrm{~g} / \mathrm{g}$, after rain event $r_{3}, q(0.1 \mathrm{~m})$ was zero during dust subevent $11-\mathrm{F}$, even when strong winds blew. Comparison of $q(0.1 \mathrm{~m})$ between subevents 11-E and 11-F (Figure 7) illustrates this point.

[45] The $q(0.1 \mathrm{~m})$ during subevent 11-E increased with $u_{*}$ when $u_{*}$ exceeded $0.3 \mathrm{~m} / \mathrm{s}$, while during subevent $11-\mathrm{F} q(0.1 \mathrm{~m})$ was almost zero even when $u_{*}$ increased to $0.48 \mathrm{~m} / \mathrm{s}$. This results indicates that $u_{*}$ increased as a result of the increase in soil moisture and then $q(0.1 \mathrm{~m})$ was zero. From Figure 6, the soil moisture threshold, which is the value when $f_{w}$ become more than one, can be estimated to be $0.013-0.015 \mathrm{~g} / \mathrm{g}$.

\subsection{Dust Concentrations Under Wet Conditions}

[46] Gillette [1977] showed by field measurements that the vertical dust flux $F$ is dependent on $u_{*}$. Its dependence was assumed to be described by the proportional relation $F=\alpha u_{*}^{a}$, where $\alpha$ and $a$ are essential empirical parameters, on the basis of observations by Nickling and Gillies [1989] and Shao et al. [1993] and modeling by Gillette and Passi [1988]. On the basis of the results of another experiment undertaken in Australia, Nickling et al. [1999] reported that $F$ was proportional to $Q$ raised to the power of 1.55. F/ $Q$ is also proportional to $p_{s}\left(D_{i}\right), \sigma_{m}$, and $\eta_{c i}$ in equation (1) [Shao, 2001] as well as to the relative clay content [Marticorena and Bergametti, 1995]. In this study, as a first approximation, we assumed that the relation between $q(z)$ and $c(z)$ was similar to that between $Q$ and $F$ : namely, when $q(z)$ increases, $c(z)$ also increases.

[47] Figure 8 shows the relationship between $c(z)$ and $u_{*}$ during subevents 11-E and 11-F. Similar to $q(z)$ (Figure 7), $c(z)$ showed major differences between subevents 11-E and $11-\mathrm{F}$, with $c(z)$ is being very low during the latter event, after soil moisture had increased. This result is not surprising because no dust emission occurs when there is no saltation (equation (1)), and is consistent with this saltation bombardment theory [Shao et al., 1993].

\subsection{The $q(z)$ With Weak Discontinuous Crusts}

[48] During event 10 , the soil surface was characterized by individual loose grains; that is, there was no crust. By event 12 , a very weak discontinuous crust had formed. Figure 9 is a photograph, taken at 0930 LT on 13 March, of the crusting pattern on the ground surface formed by the impact and subsequent drying of raindroplets that fell during precipitation events. The photo clearly shows the discontinuous nature of the small, circular crusts on the ground surface. The diameter of the circular crusts ranged from 2 to $8 \mathrm{~mm}$. These crusts were very weak and were easily destroyed by touching them.

[49] The soil moisture $\left(\omega_{\text {oven }}\right)$ level had declined to $0.012 \mathrm{~g} / \mathrm{g}$ at $1115 \mathrm{LT}$ from $0.025 \mathrm{~g} / \mathrm{g}$ at $1012 \mathrm{LT}$ (Figure 5); thus, the ground surface quickly recovered to its normal dry condition by the beginning of event 12 , but the weak crusts remained. We could not use the $q(0.05 \mathrm{~m})$ data for event 12 for the analysis because of the distortion of the flow caused

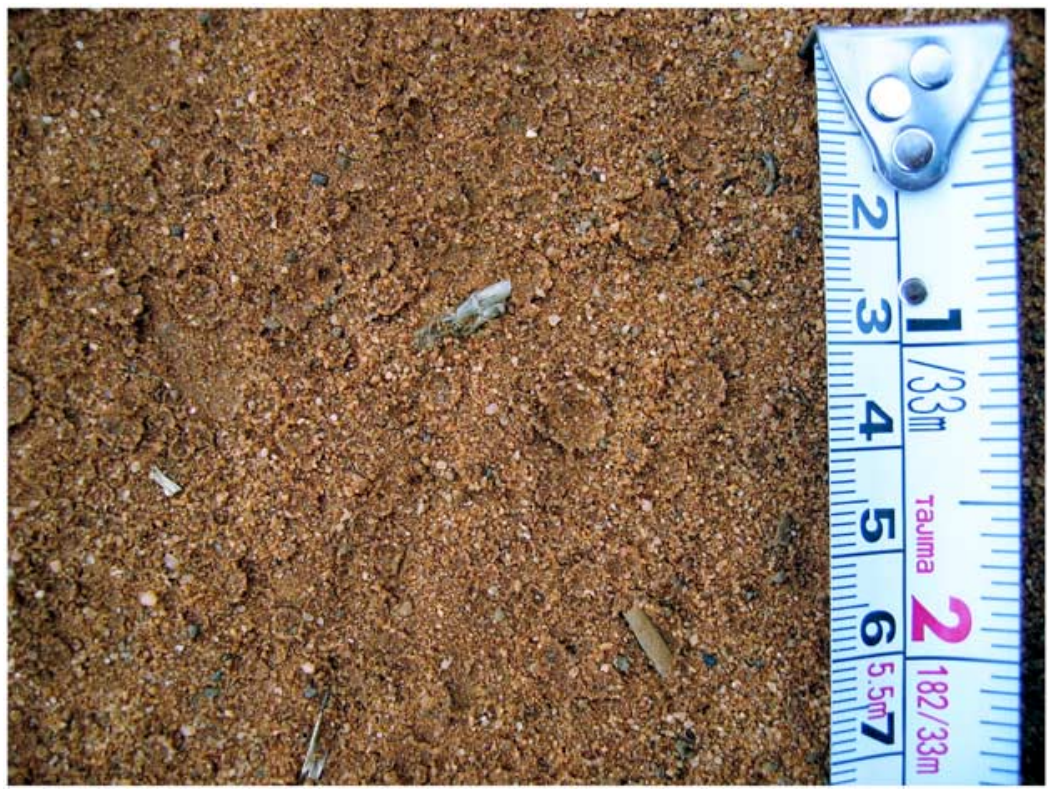

Figure 9. Photograph of weak crusts on the ground surface caused by the impacts and subsequent drying of raindrops after precipitation event $r_{4}$ taken at 0930 LT on 13 March 2006. 


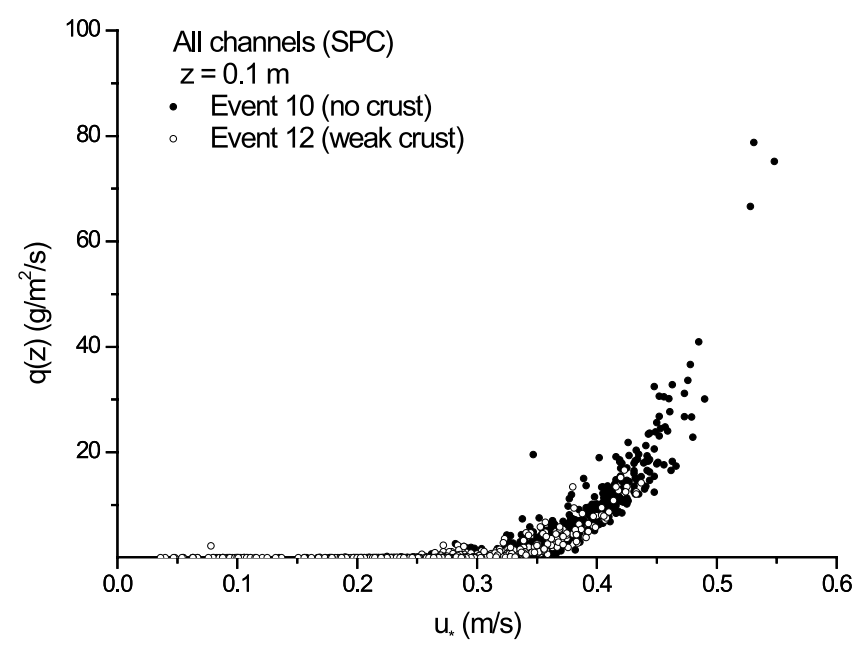

Figure 10. Relationship between $u *$ and the saltation flux $q(z)$ for event 10 (no crust) and event 12 (weak crust) at $0.1 \mathrm{~m}$ height.

by the SPC mounting pole, as mentioned in section 4.2 . Hence, we used $q(0.1 \mathrm{~m})$ data and compared event 10 with event 12 . Though the wind direction and maximum wind speed were not similar, the wind strength characteristics and the duration of each event caused by the intermittent strong winds were similar (Figure 3).

[50] Figure 10 shows the relationship between $q(z)$ and $u_{*}$ for uncrusted and weakly crusted conditions (events 10 and 12). The $q(z)$ to $u *$ relationship is almost the same for the two events. This indicates that the weak crust created by a small precipitation event had little effect on the erodibility of the surface. This is because the ground had already dried when event 12 started. These data further highlight that this weak crust was insufficient to control the erosion (saltation) levels and that the crust binding force for saltation, which is related to $f_{c r}$, was weak.

\subsection{The $c(z)$ With Weak Discontinuous Crusts}

[51] Figure 11 shows $c(1.0 \mathrm{~m})$ for events 10 and 12 . During both events, $c(1.0 \mathrm{~m})$ increased with $u_{*}$, which is not surprising because of the strong links between saltation and dust emission. However, $c(1.0 \mathrm{~m})$ during event 12 was slightly smaller than that during event 10 , indicating that $c(z)$ can vary even when $q(z)$ does not. This result indicates that the proportionality between $c(z)$ and $u *$ was dependent on ground surface conditions, such as $p_{m}(D)$ and the presence or absence of crust.

[52] Horizontal visibility at the site during event 12 was good at eye level $(1.6 \mathrm{~m})$. Empirically, visibility by the human eye is related to the concentration of fine aerosol particles, such as around $1 \mu \mathrm{m}$. Our actual experience reflects this empirical observation.

[53] In this paper, we have not discussed the height dependence of the dust concentration, nor have we performed vertical dust flux calculations. These topics will be examined in further analyses.

\subsection{Particle Size Dependence of $c(z)$ With Weak Discontinuous Crusts}

[54] The results reported in sections 5.3 and 5.4 indicate that a weak crust had little effect on $q(z)$ but did influence $c(z)$. The OPC allows the dust concentration for each particle size $\hat{c}\left(z, D_{d i}\right)$ to be examined in detail. Figure 12 shows $\hat{c}\left(z, D_{d i}\right)$ at $1 \mathrm{~m}$ height for the uncrusted (event 10) and weakly crusted (event 12) conditions. The weakly crusted surface tended to emit lower levels of fine dust particles $(0.5-3.0 \mu \mathrm{m})$. As the particle size increased, the difference is less noticeable. Coarse dust particles (3.0$7.0 \mu \mathrm{m}$ ) tended to have similar emission rates regardless of the presence of the crust. This result shows a clear particle size dependence of $c(z)$ for the weakly crusted condition. This finding explains why $c(1.0 \mathrm{~m})$ during event 12 was only slightly smaller than that during event 10 (Figure 11). This result indicates that $\hat{c}\left(z, D_{d i}\right)$ depends on the change of ground surface conditions.

[55] The point here is that even though the surface had dried out by event $12, c(z)$ was changed compared to that during event 10 . This indicates that $c(z)$ is dependent on not only the amount of water per se but the "water supply history."

\section{Discussion}

\subsection{Particle Size Distribution of in Situ Parent Soil With Weak Discontinuous Crusts}

[56] Most of dust particles aggregate even under natural air-dry conditions. Shao [2001] showed this phenomenon accounted for $p_{m}(D)$. Figures 13 and 14 show $p_{m}(D)$ and $p_{f}(D)$ as determined by the Coulter Multisizer particle counter method [McTainsh et al., 1997] at different times (on 12 and 13 March). The maximum particle size was set at $1000 \mu \mathrm{m}$. The samples were collected from 0 to $0.5 \mathrm{~cm}$ depth from the eroded uncrusted surface before precipitation $r_{1}$ on 12 March (labeled A in Figure 5) and from the weakly crusted surface after precipitation $r_{4}$ on 13 March (labeled B in Figure 5). The particle number fraction $d N(D)\left(=N_{i+1}-N_{i}\right)$ and the volume fraction $d V(D)\left(=V_{i+1}-V_{i}\right)$ for each particle size $D$ and bin number $i$ were normalized relative to the total number $N$ and the total volume $V$, respectively, of the counted particles. The normalized values were expressed as $d N(D) / N$ $(=n(D))$ and $d V(D) / V(=v(D))$.

[57] To facilitate examination of the PSD characteristics from various points of view, $p_{m}(D)$ of uncrusted and weakly

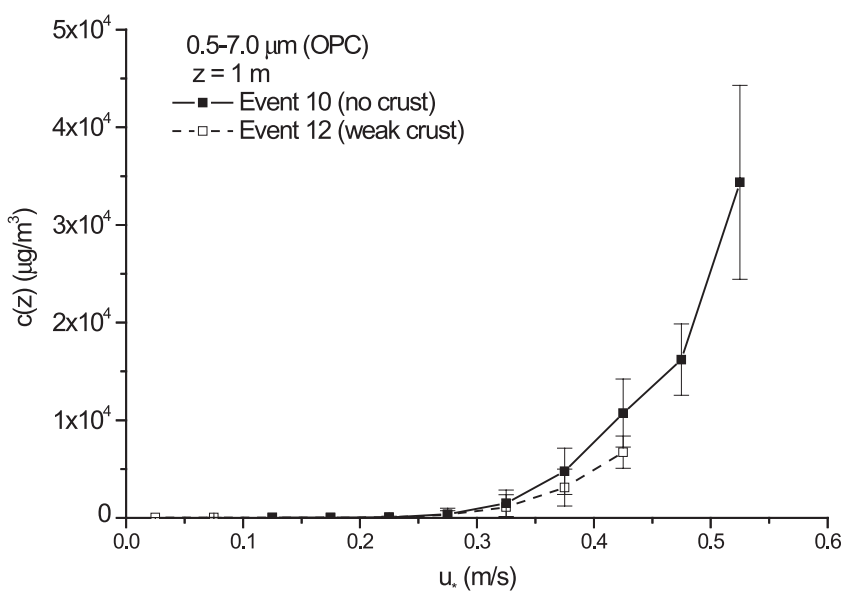

Figure 11. Relationship between $u *$ and $c(z)$ at $1 \mathrm{~m}$ height during events 10 and 12 . The data were averaged over $0.5 \mathrm{~m} / \mathrm{s}$ increments and the error bars show the standard deviation. 

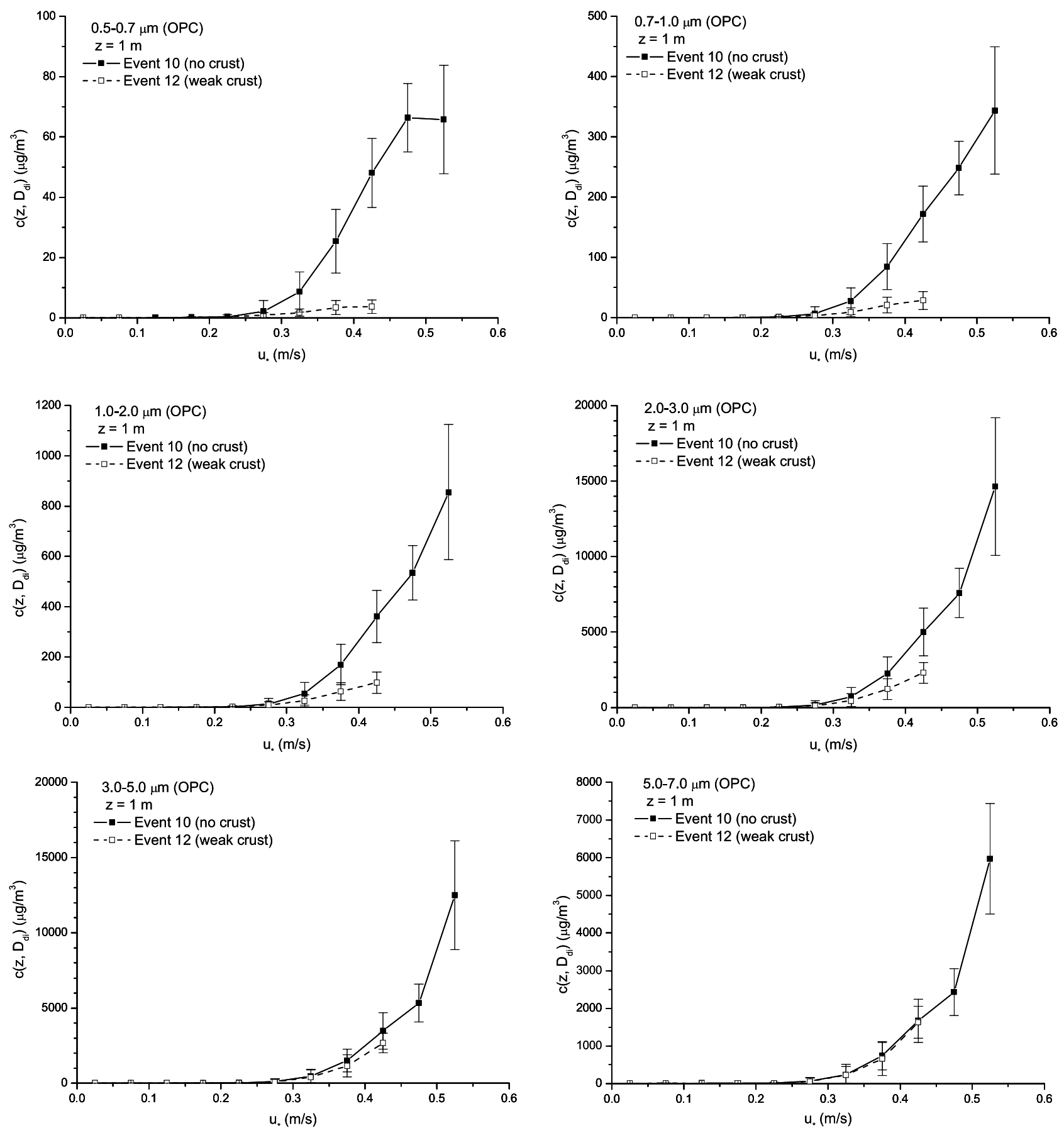

Figure 12. Relationship between $u *$ and the dust concentration $\hat{c}\left(z, D_{d i}\right)$ at $1 \mathrm{~m}$ height for event 10 (no crust) and event 12 (weak crust). The data were averaged over $0.5 \mathrm{~m} / \mathrm{s}$ increments and the error bars show the standard deviation.

crusted soils is presented in several different ways in Figure 13: $n(D)$ after logarithmic transformation in Figure 13a, $v(D)$ without logarithmic transformation in Figure 13b, and $v(D)$ after logarithmic transformation in Figure 13c. The $n(D)$ distribution shows the characteristic PSD over a wide range of particle sizes from fine to coarse. The coarse fraction increased after precipitation, with a corresponding decrease in the fine fraction (Figure 13a), but the volumetric PSD shows that the sand particles distribution did not change (Figure 13b). In addition, the volume of dust particles showed a decrease after precipitation (Figure 13c). These results suggest two possible explanations: the finer particles may have been picked up by wind during dust events 10 and 11, or they may have become bound to the larger particles during the precipitation events.

[58] The comparison between $p_{m}(D)$ and $p_{f}(D)$ before precipitation events (Figures $14 \mathrm{a}$ and $14 \mathrm{~b}$ ) shows that this difference is small. This result indicates that dust particles were not aggregated on 12 March and available dust was easily eroded. This result is consistent with observations that a number of dust events occurred at the site during the IOP before precipitation events. However, after precipita- 
a

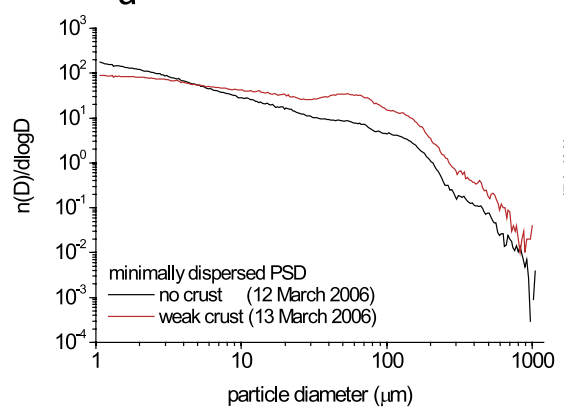

b

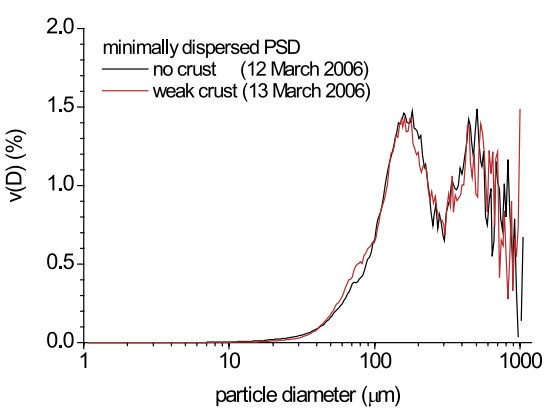

C

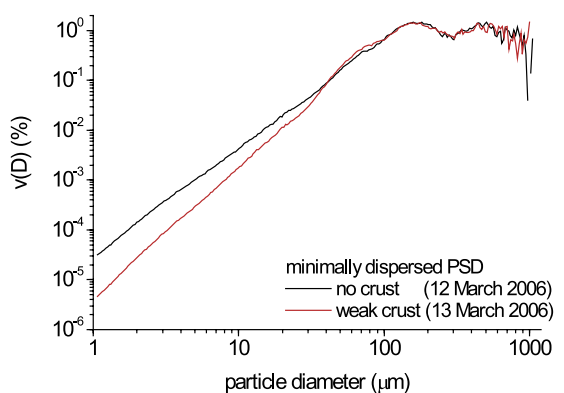

Figure 13. Minimally dispersed particle size distributions of the in situ parent soil taken from the uncrusted surface before precipitation $r_{1}$ at 1031 LT on 12 March 2006 (black lines) and from the weakly crusted surface after precipitation $r_{4}$ at $1012 \mathrm{LT}$ on 13 March 2006 (red lines) at $0-0.5 \mathrm{~cm}$ depth, showing the changes in the PSD with time; $n(D)$ is the number of particles of particle size $D$ normalized relative to the total number of particles; $v(D)$ is the same as $n(D)$ but on a volumetric basis. Each plot was drawn with different $y$-axis expressions: (a) $n(D)$ with log axis, (b) $v(D)$ with normal axis, and (c) $v(D)$ with $\log$ axis.

tion events (Figures 14c and 14d), a large difference in the proportion of dust particles of $p_{m}\left(D_{i}\right)$, especially with particle sizes below $10 \mu \mathrm{m}$, was observed. This indicates that a number of aggregated dust particles were present on the weakly crusted surface and the proportion of available
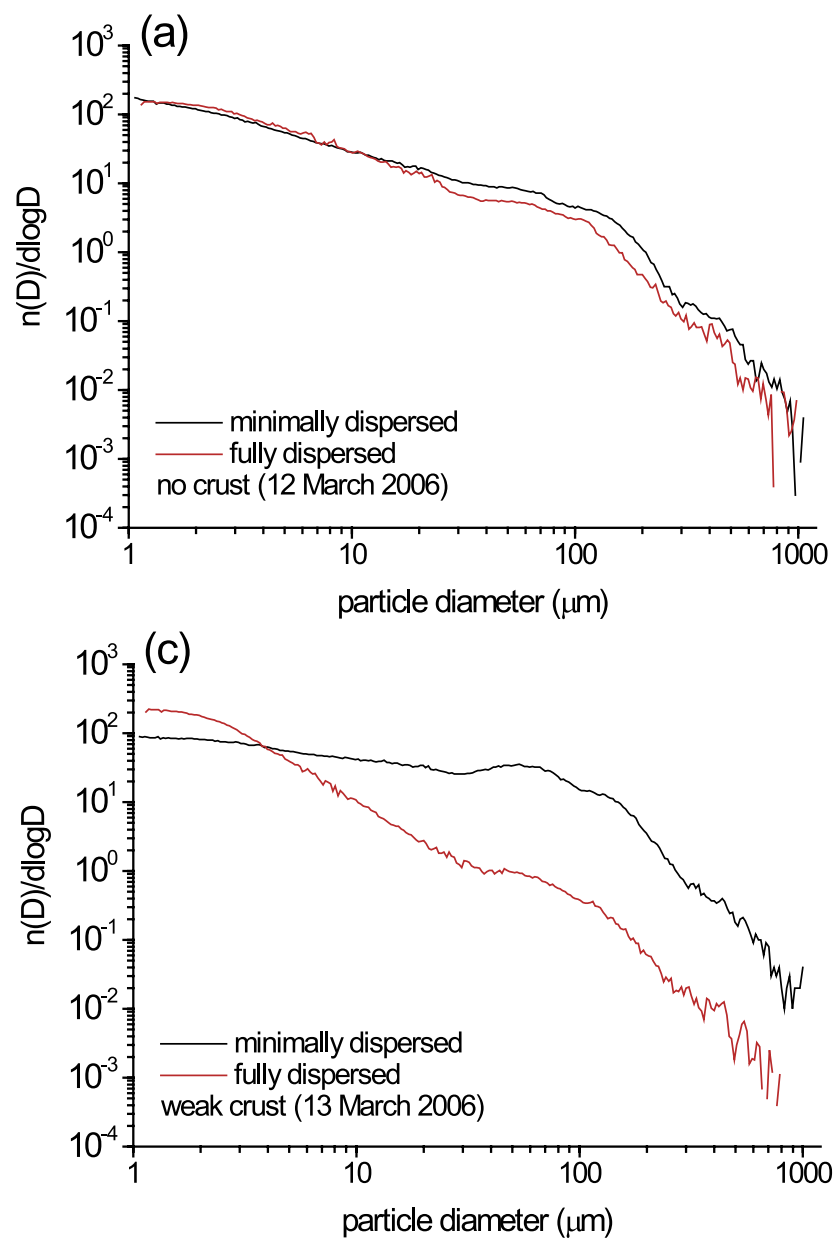

dust for emission was small. It is assumed that $p_{m}\left(D_{i}\right)$ of dust particles is strongly related to crust and aggregation binging forces for dust emission.

[59] A possible explanation for these observations is that dust particles (1) adhere to the sand particles or (2) aggregate
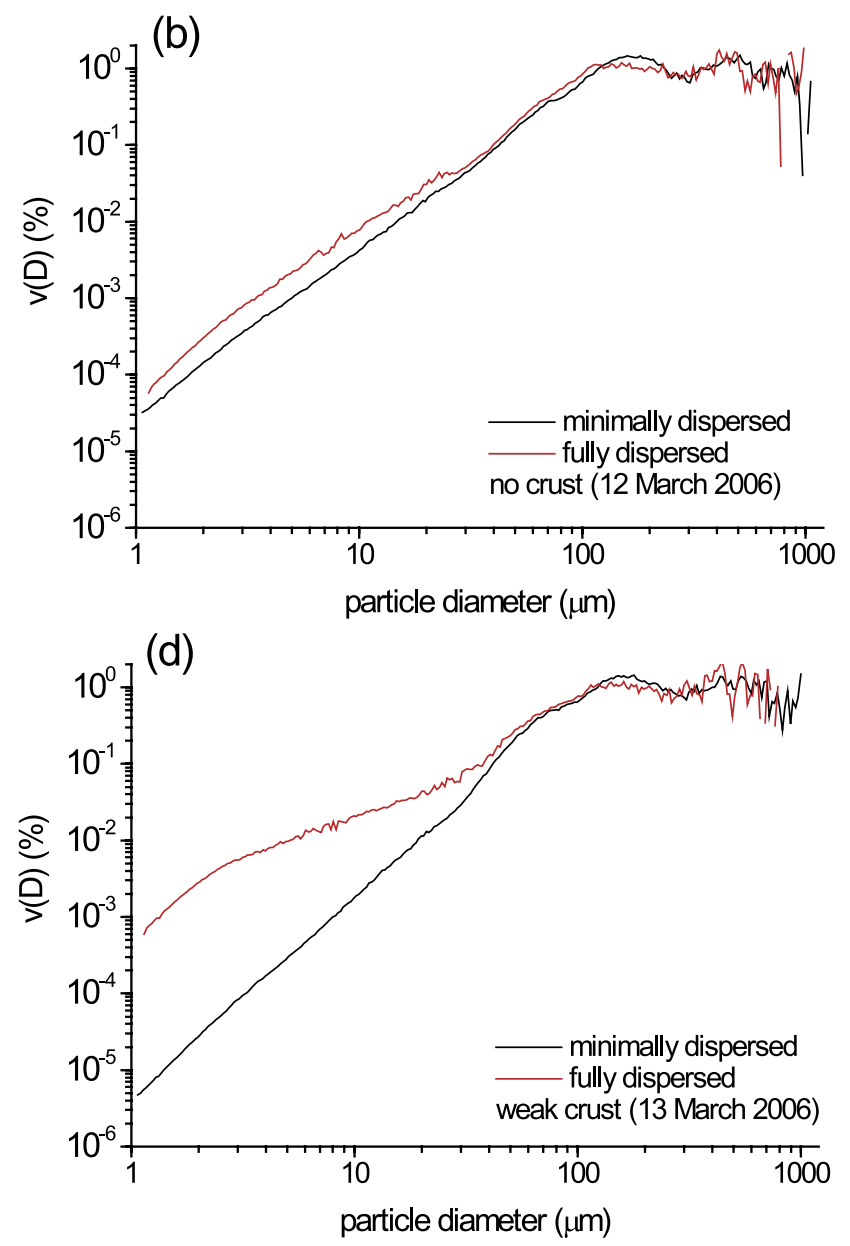

Figure 14. Particle size distributions of the surface parent soil ( $0-0.5 \mathrm{~cm}$ depth). (a, b) From the uncrusted surface at 1031 LT on 12 March 2006 (before precipitation $r_{1}$ ) and (c, d) from the weakly crusted surface after precipitation $r_{4}$ at 1012 LT on 13 March 2006, under minimally and fully dispersed conditions. 


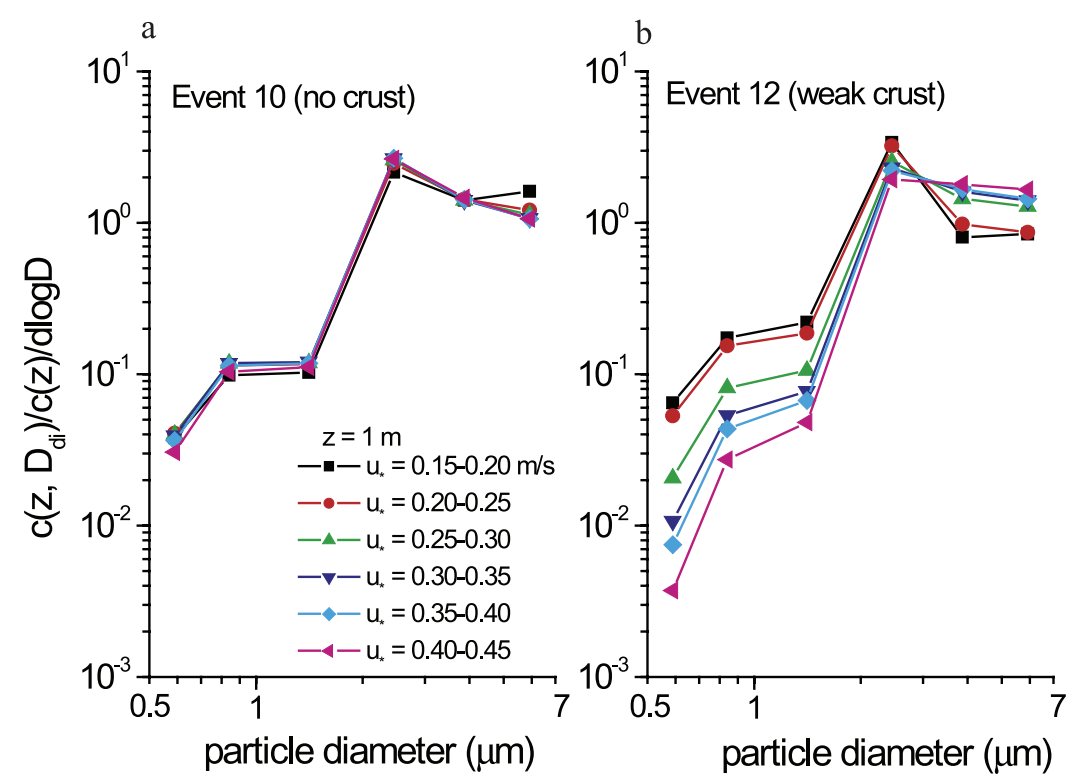

Figure 15. Particle size distributions of suspended dusts measured by OPC at $1 \mathrm{~m}$ height during (a) event 10 (no crust) and (b) event 12 (weak crust) under different friction wind velocity conditions.

together when the soil is wetted by precipitation events and then dried by evaporation. Therefore, once a crust has formed, the dust particles are "locked up" and not available for dust emission. Even if the crust is broken up by the saltation activity, we assume the $c(z)$ would not return to the event 10 condition immediately because the finer dust particles would still be more strongly aggregated.

\subsection{Particle Size Distribution of Suspended Dust With Weak Discontinuous Crusts}

[60] Figure 15 shows PSDs of suspended dusts $p_{s}(D)$ under different crust and wind speed conditions based on $\hat{c}\left(z, D_{d i}\right)$ data. Dust particles which have small binding forces can be easily lifted by aerodynamic entrainment [Loosmore and Hunt, 2000]. The $p_{s}(D)$ for the uncrusted condition does not change whether $u_{*}$ is strong (not necessary extremely strong) or not (Figure 15a). This is because the difference between $p_{m}(D)$ and $p_{f}(D)$ was small (Figure 14b), which means the parent soil was strongly disturbed on 12 March. This result agrees with the theoretical representation of $p_{s}(D)$, namely, $p_{s}(D) \rightarrow p_{m}(D)$ for weak erosion and $p_{s}(D) \rightarrow p_{f}(D)$ for strong erosion [Shao, 2001].

[61] A clear difference is seen for the weakly crusted condition (Figure 15b). Finer dust fraction decreases with increase of $u_{*}$, that is, the PSD mode changes from fine to coarse. This means coarser dust particles more erodible when $u *$ increases for the weakly crusted condition.

[62] Hillel [1998] mentioned that soil moisture was retained in the soil as water wedges and as water films when soil moisture was lower than the field capacity. When dust particles aggregate together or adhere to the surfaces of sand grains because of soil moisture, it is assumed that the contact area of the water formed between sand and coarse dust may be relatively large compared with that between sand and fine dust. A larger contact area evaporates more easily (quickly) than a smaller one as the soil dries. This assumes that interparticle cohesive force for coarser dust particles is weaker than that for finer dust particles. Iversen and White [1982] described the increased of $u_{*}$ for finer particles associated with finer particle size. The interparticle cohesive force might be more enhanced when the weak crust was formed.

[63] As a result, we can explain that (1) suspended dust particles are particle size dependent, $(2) p_{s}(D)$ depends on $u_{*}$ and ground surface condition, and (3) aggregation binding force of coarser dust particles would weaken as the soil dries.

\section{Conclusion}

[64] Using both SPCs and OPCs, we observed the relationships between $q(z)$ and $c(z)$ under different ground surface conditions: (1) wet or dry, and (2) uncrusted or weakly crusted conditions, resulting from the impact and subsequent drying of raindroplets after a small amount of precipitation, in a fallow field, formerly cultivated with wheat, in Australia.

[65] This study clarified that soil moisture enhanced crust and aggregation and that $c(z)$ depend on ground surface conditions.

[66] First, we confirmed that when $q(z)$ decreased because of an increase of soil moisture $c(z)$ also decreased (Figures 7 and 8). This finding is in agreement with the saltation bombardment theory.

[67] Second, $q(z)$ under the uncrusted condition was similar to that under weakly crusted condition, but $c(z)$ decreased slightly in the weakly crusted conditions (Figures 10 and 11). This is because the weakly crusted surface tended to emit lower amounts of fine dust particles $(0.5-3.0 \mu \mathrm{m})$, though it tended to emit coarse dust particles at similar rates $(3.0-7.0 \mu \mathrm{m})$ regardless of the presence of the crust (Figure 12). This result indicated that the proportionality between $c(z)$ and $u_{*}$ was dependent on ground surface conditions, such as $p_{m}(D)$ and the presence or absence of crust. The point here was that even though the surface had dried out, $c(z)$ was changed. This indicated that $c(z)$ was 
dependent on not only the amount of water per se but the "water supply history."

[68] Third, $p_{m}(D)$ and $p_{f}(D)$ showed that many available dust particles have been present on the ground before precipitation, while they became strongly aggregated under the weakly crusted condition after precipitation (Figures 13 and 14). It was assumed that $p_{m}(D)$ of dust particles was strongly related to crust and aggregation binging forces for dust emission.

[69] Finally, the mode change of $p_{s}(D)$ from fine to coarse with increase of $u_{*}$ for the weakly crusted condition assumed that coarser dust particles more erodible (Figure 15a). The $p_{s}(D)$ for the uncrusted condition did not change whether $u_{*}$ was strong or not (Figure 15b). These results agreed with the theory described by Shao [2001].

[70] Acknowledgments. We thank Michel Case for his support of our field and laboratory work. The Lower Murray-Darling Catchment Management Authority financially supported, procured storage for equipment during field seasons, and hosted this research in the catchment. Ned Byrnes and Patty Byrnes kindly lent us their base camp lodges to use during our field observations. The Doyle family allowed us to use an excellent observation site on their property. This research was financially supported by a Grant-in-Aid for Scientific Research (A) from Japan Society for the Promotion of Science (17201008) and (20244078), and by ISAPStipendum from DAAD (Deutscher Akademischer Austausch Dienst) austauschprogramm

\section{References}

Alfaro, S. C., and L. Gomes (2001), Modelling mineral aerosol production by wind erosion: Emission intensities and aerosol size distributions in source areas, J. Geophys. Res., 106(D16), 18,075-18,084, doi:10.1029/ 2000JD900339.

Anderson, R. S. (1986), Erosion profiles due to particles entrained by wind: Application of an eolian sediment-transport model, Geol. Soc. Am. Bull., 97 , 1270-1278, doi:10.1130/0016-7606(1986)97<1270:EPDTPE >2.0.CO;2. Bagnold, R. A. (1941), The Physics of Blown Sand and Desert Dunes, 265 pp., Methuen, London.

Campbell Scientific, Inc. (2002), CS616 water content reflectometer instruction manual, report, 34 pp., Logan, Utah.

Chepil, W. S. (1956), Influence of moisture on erodibility of soil by wind, Soil Sci. Soc. Am. J., 20, 288-292.

Fécan, F., B. Marticorena, and G. Bergametti (1999), Parameterization of the increase of the aeolian erosion threshold wind friction velocity due to soil moisture for arid and semi-arid areas, Ann. Geophys., 17, 149-157, doi:10.1007/s005850050744.

Gillette, D. A. (1977), Fine particulate emissions due to wind erosion, Trans. Am. Soc. Agric. Eng., 20, 890-897.

Gillette, D. A., and R. Passi (1988), Modeling dust emission caused by wind erosion, J. Geophys. Res., 93(D11), 14,233-14,242, doi:10.1029/ JD093iD11p14233.

Gillette, D. A., J. Adams, A. Endo, and D. Smith (1980), Threshold velocities for input of soil particles into the air by desert soils, J. Geophys. Res., 85(C10), 5621-5630, doi:10.1029/JC085iC10p05621.

Gomes, L., G. Bergametti, G. Coudé-Gaussen, and P. Rognon (1990), Submicron desert dusts: A sandblasting process, J. Geophys. Res., 95(D9), 13,927-13,935, doi:10.1029/JD095iD09p13927.

Hillel, D. (1998), Environmental Soil Physics, 771 pp., Academic, San Diego, Calif.

Huebert, B. J., T. Bates, P. B. Russell, G. Shi, Y. J. Kim, K. Kawamura, G. Carmichael, and T. Nakajima (2003), An overview of ACE-Asia: Strategies for quantifying the relationships between Asian aerosols and their climatic impacts, J. Geophys. Res., 108(D23), 8633, doi:10.1029/ 2003JD003550

Ishizuka, M., and M. Mikami (2005), Measurement of soil water content in a hyper-arid environment using time-domain reflectometry sensors, Hydrol. Processes, 19(19), 3911-3920, doi:10.1002/hyp.5989.

Ishizuka, M., M. Mikami, Y. Yamada, F. J. Zeng, and W. Gao (2005a), An observational study of soil moisture effects on wind erosion at a gobi site in the Taklimakan Desert, J. Geophys. Res., 110, D18S03, doi:10.1029/ 2004JD004709.

Ishizuka, M., M. Mikami, F. J. Zeng, W. Gao, and Y. Yamada (2005b), Measurements of soil water content using time domain reflectometry sensor and water vapor in the surface soil layer at the gobi site in the
Taklimakan Desert, J. Meteorol. Soc. Jpn., 83(6), 987-999, doi:10.2151/ jmsj.83.987.

Iversen, J. D., and B. R. White (1982), Saltation threshold on Earth, Mars and Venus, Sedimentology, 29, 111-119, doi:10.1111/j.1365-3091.1982. tb01713.x.

Iversen, J. D., J. B. Pollack, R. Greeley, and B. R. White (1976), Saltation threshold on Mars: The effect of interparticle force, surface roughness, and low atmospheric density, Icarus, 29, 381-393, doi:10.1016/00191035(76)90140-8.

Kaufman, Y. J., D. Tanré, and O. Boucher (2002), A satellite view of aerosols in the climate system, Nature, 419, 215-223, doi:10.1038/nature01091.

Leys, J. F., and D. J. Eldridge (1998), Influence of cryptogamic crust disturbance to wind erosion on sand and loam rangeland soils, Earth Surf. Processes Landforms, 23, 963-974, doi:10.1002/(SICI)10969837(1998110)23:11<963::AID-ESP914>3.0.CO;2-X.

Leys, J. F., G. H. McTainsh, T. Koen, B. Mooney, and C. Strong (2005), Testing a statistical curve-fitting procedure for quantifying sediment populations within multi-modal particle-size distributions, Earth Surf. Processes Landforms, 30, 579-590, doi:10.1002/esp.1159.

Loosmore, G. A., and J. R. Hunt (2000), Dust resuspension without saltation, J. Geophys. Res., 105(D16), 20,663-20,671, doi:10.1029/ 2000JD900271.

Lu, H., and Y. Shao (1999), A new model for dust emission by saltation bombardment, J. Geophys. Res., 104(D14), 16,827-16,842, doi:10.1029/ 1999JD900169.

Marticorena, B., and G. Bergametti (1995), Modeling the atmospheric dust cycle: 1. Design of a soil-derived dust emission scheme, J. Geophys. Res., 100(D8), 16,415-16,430, doi:10.1029/95JD00690.

McKenna-Neuman, C., and C. Maxwell (1999), A wind tunnel study of the resilience of three fungal crusts to particle abrasion during Aeolian sediment transport, Catena, 38(2), 151-173, doi:10.1016/S0341-8162(99)00043-0.

McKenna-Neuman, C., and W. G. Nickling (1989), A theoretical and wind tunnel investigation of the effect of capillarity water on the entrainment of sediment by wind, Can. J. Soil Sci., 69, 79-96.

McKenna-Neuman, C. C. D. Maxwell, and J. W. Boulton (1996), Wind transport of sand surfaces crusted with photoautotrophic microorganisms, Catena, 27(3-4), 229-247, doi:10.1016/0341-8162(96)00023-9.

McTainsh, G. H., A. W. Lynch, and R. C. Burgess (1990), Wind erosion in eastern Australia, Aust. J. Soil Res., 28, 323-339, doi:10.1071/ SR9900323.

McTainsh, G. H., A. W. Lynch, and R. Hales (1997), Particle-size analysis of aeolian dusts, soils and sediments in very small quantities using a Coulter Multisizer, Earth Surf. Processes Landforms, 22, 1207-1216, doi:10.1002 (SICI)1096-9837(199724)22:13<1207::AID-ESP820>3.0.CO;2-K.

Mikami, M., T. Toya, and N. Yasuda (1996), An analytical method for the determination of the roughness parameters over complex regions, Boundary Layer Meteorol., 79, 23-33, doi:10.1007/BF00120073.

Mikami, M., T. Aoki, M. Ishizuka, S. Yabuki, Y. Yamada, W. Gao, and F. J. Zeng (2005a), Observation of number size distribution of desert aerosols in the south of the Taklimakan desert, China, J. Meteorol. Soc. Jpn., 83A, $31-43$.

Mikami, M., Y. Yamada, M. Ishizuka, T. Ishimaru, W. Gao, and F. J. Zeng $(2005 \mathrm{~b})$, Measurement of saltation process over gobi and sand dunes in the Taklimakan desert, China, with newly developed sand particle counter, J. Geophys. Res., 110, D18S02, doi:10.1029/2004JD004688.

Mikami, M., et al. (2006), Aeolian dust experiment on climate impact: An overview of Japan-China Joint Project ADEC, Global Planet. Change, 52, 142-172, doi:10.1016/j.gloplacha.2006.03.001.

Nickling, W. G. (1984), The stabilizing role of bonding agents on the entrainment of sediment by wind, Sedimentology, 31, 111-117, doi:10.1111/j.1365-3091.1984.tb00726.x.

Nickling, W. G., and M. Ecclestone (1981), The effects of soluble salts on the threshold shear velocity of fine sand, Sedimentology, 28, 505-510, doi:10.1111/j.1365-3091.1981.tb01698.x.

Nickling, W. G., and J. A. Gillies (1989), Emission of fine-grained particulates from desert soils, in Paleoclimatology and Paleometeorology: Modern and Past Patterns of Global Atmospheric Transport, NATO ASI Ser. $C$, vol. 282, edited by M. Leinen and M. Sarnthein, pp. 133-165, Kluwer Acad. Publishers, Dordrecht, Netherlands

Nickling, W. G., G. H. McTainsh, and J. F. Leys (1999), Dust emissions from the channel country of western Queensland, Australia, Z. Geomorphol., $116,1-17$.

Oke, T. R. (1978), Boundary Layer Climates, 435 pp., Methuen, London. Rice, M. A., B. B. Willetts, and I. K. McEwan (1996a), Observations of collisions of saltating grains with a granular bed from high-speed cine-film, Sedimentology, 43, 21-32, doi:10.1111/j.1365-3091.1996.tb01456.x.

Rice, M. A., B. B. Willetts, and I. K. McEwan (1996b), Wind erosion of crusted soil sediments, Earth Surf. Processes Landforms, 21, 279-293, doi:10.1002/(SICI)1096-9837(199603)21:3<279::AID-ESP633>3.0. $\mathrm{CO} ; 2-\mathrm{A}$. 
Rice, M. A., C. E. Mullins, and I. K. McEwan (1997), An analysis of soil crust strength in relation to potential abrasion by saltating particles, Earth Surf. Processes Landforms, 22(9), 869-883, doi:10.1002/(SICI)10969837(199709)22:9<869::AID-ESP785>3.0.CO;2-P.

Routbort, J. L., R. O. Scattergood, and E. W. Kay (1980), Erosion of silicon single crystals, J. Am. Ceram. Soc., 63, 635-640, doi:10.1111/j.11512916.1980.tb09851.x.

Shao, Y. (2000), Physics and Modeling of Wind Erosion, 389 pp., Kluwer Acad., Dordrecht, Netherlands.

Shao, Y. (2001), A model for mineral dust emission, J. Geophys. Res., 106(D17), 20,239-20,254, doi:10.1029/2001JD900171.

Shao, Y. (2004), Simplification of a dust emission scheme and comparison with data, J. Geophys. Res., 109, D10202, doi:10.1029/2003JD004372.

Shao, Y. (2005), A similarity theory for saltation and application to aeolian mass flux, Boundary Layer Meteorol., 115, 319-338, doi:10.1007/ s10546-004-4632-0.

Shao, Y., and C. H. Dong (2006), A review on east Asian dust storm climate, modelling and monitoring, Global Planet. Change, 52, 1-22, doi:10.1016/j.gloplacha.2006.02.011.

Shao, Y., and H. Lu (2000), A simple expression for wind erosion threshold friction velocity, J. Geophys. Res., 105(D17), 22,437-22,443, doi:10.1029/2000JD900304

Shao, Y., and M. Mikami (2005), Heterogeneous saltation: Theory, observation and comparison, Boundary Layer Meteorol., 115, 359-379, doi:10.1007/s10546-004-7089-2.

Shao, Y., M. R. Raupach, and P. A. Findlater (1993), The effect of saltation bombardment on the entrainment of dust by wind, J. Geophys. Res., 98(D7), 12,719-12,726, doi:10.1029/93JD00396.

Sokolik, I. N., and O. B. Toon (1996), Direct radiative forcing by anthropogenic airborne mineral aerosols, Nature, 381, 681-683, doi:10.1038/ $381681 \mathrm{a} 0$

Tegen, I., A. A. Lacis, and I. Fung (1996), The influence on climate forcing of mineral aerosols from disturbed soils, Nature, 380, 419-422, doi:10.1038/380419a0.
Uematsu, M., R. Duce, J. Prospero, L. Chen, J. Merrill, and R. McDonald (1983), The transport of mineral aerosol from Asia over the North Pacific Ocean, J. Geophys. Res., 88(C9), 5343-5352, doi:10.1029/ JC088iC09p05343.

Uno, I., et al. (2006), Dust model intercomparison (DMIP) study over Asia: Overview, J. Geophys. Res., 111, D12213, doi:10.1029/2005JD006575.

Yamada, Y., M. Mikami, and H. Nagashima (2002), Dust particle measuring system for streamwise dust flux, J. Arid Land Stud., 11(4), 229-234.

Zender, C. S., H. Bian, and D. Newman (2003), Mineral dust entrainment and deposition (DEAD) model: Description and 1990s dust climatology, J. Geophys. Res., 108(D14), 4416, doi:10.1029/2002JD002775.

Zobeck, T. M., and D. W. Fryrear (1986), Chemical and physical characteristics of windblown sediment 1. Quantities and physical characteristics, Trans. ASAE, 29(4), 1032-1036.

S. Heidenreich and J. Leys, Department of Environment and Climate Change, New South Wales Government, PO Box 462, 9127 Kamilaro Highway, Gunnedah, NSW 2380, Australia. (Stephan.Heidenreich@) environment.nsw.gov.au; john.leys@environment.nsw.gov.au)

M. Ishizuka, Department of Safety Systems Construction Engineering, Faculty of Engineering, Kagawa University, 2217-20 Hayashi-cho, Takamatsu, Kagawa, 761-0396, Japan. (ishizuka@eng.kagawa-u.ac.jp)

G. H. McTainsh, Australian Rivers Institute, Griffith University, Nathan Campus, 170 Kessels Road, Nathan, QLD 4111, Australia. (G.McTainsh@ griffith.edu.au)

M. Mikami, Meteorological Research Institute, Japan Meteorological Agency, 1-1 Nagamine, Tsukuba, Ibaraki, 305-0052, Japan. (mmikami@ mri-jma.go.jp)

Y. Shao, Institute for Geophysics and Meteorology, University of Cologne, Albertus-Magnus-Platz, D-50674 Cologne, Germany. (yshao@ meteo.uni-koeln.de)

Y. Yamada, Rapid Engineering Team, Advanced Technology Support Division, RIKEN, Hirosawa, Wako, Saitama, 351-0198, Japan. (yamadayu@ riken.jp) 